\title{
Las aportaciones de los manuscritos pictográficos al estudio del juego de pelota
}

$\mathrm{E}$ 1 estudio etnohistórico de los manuscritos pictográficos prehispánicos y coloniales es una disciplina rigurosa y difícil, muy distinta, en sus métodos, del análisis de las fuentes escritas de los cronistas. Cada documento es único y merece un estudio específico, conforme a su lógica interna, su procedencia y su temática (histórica, adivinatoria, registro de impuestos, cartografía, entre otros). Además, los desciframientos implican la lectura lingüística de los pictogramas. Se necesita también considerar la coherencia por grupo (Borgia) o por origen (Puebla, documentos nahuas, mixtecos, etcétera).

Como arqueólogo, en el marco de mi interés personal por el juego de pelota y su contexto arquitectónico, a pesar de esas consideraciones básicas, enfocaré mi análisis en una perspectiva transversal muy distinta ${ }^{\mathrm{I}}$ para esbozar una visión temática global: ¿qué aportaciones arqueológicas nos proporcionan las múltiples representaciones de canchas de juego de pelota de los códices y manuscritos prehispánicos y coloniales?

En esta síntesis traté de registrar sistemáticamente todas las ocurrencias, de las más grandes o complejas (Borbónico, Borgia, entre otros) hasta las menores (Códice García Granados, Mapa de Cuaubtinchan 2), ${ }^{2}$ para tratar de entender

I. Silvia Garza de González, "La arquitectura en los códices genealógicos", en Las representaciones de arquitectura en la arqueología de América, ed. Daniel Schávelzon, vol. I (México: Universidad Nacional Autónoma de México, 1982), 24I-258.

2. Robert H. Barlow, "Los caciques precortesianos de Tlatelolco en el Códice García Gra- 
sus funciones, su simbolismo y su significado, en una perspectiva interdisciplinaria.

\section{Los datos}

A lo largo de mi investigación ${ }^{3}$ registré un total de 145 representaciones procedentes de 47 manuscritos, repartidas en 120 folios. Gracias a las sugerencias y sobre todo a las críticas de colegas y maestros, añadí posteriormente unas doce imágenes, sacadas de manuscritos como el Códice Tudela,${ }^{4}$ el Selden,, 5 los Lienzos y Mapas Antonio de León, ${ }^{6}$ Egerton, Metlatoyuca, ${ }^{7}$ Santo Tomás Ocotepeque y Quauhquechollan. ${ }^{9}$ Debo reconocer además que este total de 145 representaciones resultaba erróneo, porque me equivoqué unas veces, por ejemplo en aquellas muy similares del Códice Mendoza ${ }^{\mathrm{IO}}$ y de la Matrícula de tributos, ${ }^{\mathrm{II}}$

nados (Techialoyan Q.)”, en Memorias de la Academia Mexicana de la Historia IV, núm. 4 (1945): 467-483; Bente Bittman Simons, Los mapas de Cuauhtinchan y la Historia Tolteca-Chichimeca, vol. 5 (México: Instituto Nacional de Antropología e Historia, 1968).

3. Eric Taladoire, Les Terrains de jeu de balle en Mésoamérique et dans le sud-ouest des EtatsUnis, Mission Archéologique et Ethnologique Française au Mexique, Études Mésoaméricaines (México: CEMCA, 198I), 4.

4. Códice Tudela, facsímil, anotado por José Tudela de la Orden (Madrid: Ediciones Cultura Hispánica del Instituto de Cooperación Iberoamericana, 198I).

5. Cottie A. Burland, Selden Roll: An Ancient Mexican Picture Manuscript in the Bodleian Library at Oxford, Monumenta Americana, vol. 2 (Berlín: Gebr. Mann, 1955); Alfonso Caso, Interpretación del Códice Selden 3135 (A.2) (México: Sociedad Mexicana de Antropología, 1964).

6. Alfonso Caso, "Los lienzos mixtecos de Ihuitlán y Antonio de León”, en Homenaje a don Pablo Martínez del Río (México: Universidad Nacional Autónoma de México-Instituto Nacional de Antropología e Historia/mcc/Sociedad Mexicana de Antropología, 196I), 237-274.

7. John Glass, Catálogo de la Colección de Códices (México: Instituto Nacional de Antropología e Historia-Museo Nacional de Antropología, 1964).

8. Alfonso Caso, "Mapa de Santo Tomás Ocotepeque, Oaxaca”, en Summa Antropológica en Homenaje a Roberto J. Weitlaner (México: Instituto Nacional de Antropología e Historia, I966), I3I-I37.

9. El lienzo de la conquista Quauhquechollan, catálogo de la exposición (Guatemala: Universidad Francisco Marroquín, 2009).

Io. Clark J. Cooper, Codex Mendoza: The Mexican Manuscript Known as the Collection of Mendoza and Preserved in the Bodleian Library, Oxford (Londres: Waterlow and Sons, 1938).

II. Matricula de tributos, comentarios de Frances Berdan y Jacqueline de Durand-Forest (Graz: Akademische Druck- und Verlagsanstalt, 1980). 
como lo notó Nicholas Hellmuth. ${ }^{12}$ El total efectivo giraba en realidad alrededor de 140 imágenes.

La publicación ulterior de varios documentos que desconocía en esta época (como el Códice Moctezuma) ${ }^{\mathrm{r3}}$ y las preciosas aportaciones de unos colegas ${ }^{\mathrm{I4}}$ me permitieron ampliar ligeramente el corpus, aunque sin verdaderas modificaciones. Actualmente, he registrado 157 representaciones repartidas en 58 manuscritos y I22 folios (anexos I, 5). Entre los nuevos manuscritos que logré incluir figuran los Códices Becker Iy II, ${ }^{15}$ el Lienzo de Tlapiltepec ${ }^{16}$ (fig. I), para la zona mixteca, los códices Mexicano ${ }^{17}$ y de Moctezuma, ${ }^{18}$ para el altiplano y la imagen muy significativa de la obra de Muñoz Camargo, ${ }^{19}$ para Tlaxcala. ${ }^{20}$ Cualquiera que sea el interés intrínseco de cada una, esas adiciones no modifican drásticamente la repartición global de las ilustraciones (anexo I). Casi la totalidad de ellas proceden del altiplano lato sensu, del área mixteca y de la región intermedia (el grupo Borgia). ${ }^{21}$ Fuera de esas áreas, sólo existe

I2. Nicholas Hellmuth, Notes on the Ballcourts Pictured in I6th Century Mexican Codices (Cocoa, Florida: FlaAR, 1995).

13. Xavier Noguez, "Códice Moctezuma", Arqueología Mexicana XVI, núm. 95 (enerofebrero de 2009): 84-85.

I4. Henry B. Nicholson y Eloise Quiñones Keber, "Ballcourt Images in Central Mexican Native Tradition Pictorial Manuscripts", en The Mesoamerican Ballgame, eds. Vernon Scarborough y David Wilcox (Tucson: University of Arizona Press, I99I), II9-I33; Emilie Carreón Blaine, Le Tzompantli et le jeu de balle. Relation entre deux espaces rituels, Paris Monographs in American Archaeology 32 (Óxford: B.A.R. International Series 2545, 2013); Hellmuth, Notes on the Ballcourts Pictured in I6th Century; John F. Molloy, "Ball Courts and the Oaxaca Codices", ms. presented at the International Symposium on the Mesoamerican Ballgame and Ballcourts, Tucson.

I5. Codex Becker I, ed. Karl Nowotny (Graz: Akademische Druck- und Verlagsanstalt, 196I); Codex Becker II, ed. Karl Nowotny (Graz: Akademische Druck- und Verlagsanstalt, 196I).

I6. Manuel A. Hermann Lejarazu, "El lienzo de Tlapiltepec", Arqueología Mexicana XVIII, núm. I06 (2010): I6-I7.

17. "Codex mexicanus, núm. 23-24, de la Bibliotèque Nationale de Paris", ed. Ernst Menguin, Journal de la Sociétè des Américanistes, vol. 4I (1952): 387-498.

18. Noguez, "Códice Moctezuma", 84-85.

19. Diego Muñoz Camargo, Historia de Tlaxcala (México: Innovación, 1979).

20. Manuel Carrera Stampa, "Algunos aspectos de la Historia de Tlaxcala de Diego Muñoz Camargo", en Estudios de Historiografía de la Nueva España (México: El Colegio de MéxiCo, 1945), 9I-I42.

2I. Karl Nowotny, Tlacuilolli: die mexikanischen Bilderhandschriften stil und Inhatl mit einem Katalogder Codex Borgia Gruppe, Monumenta Americana 3 (Berlín: Gebr. Mann Berlag). 
DOI: http://dx.doi.org/10.22201/iie.18703062e.2015.106.2544

I84

ERIC TALADOIRE

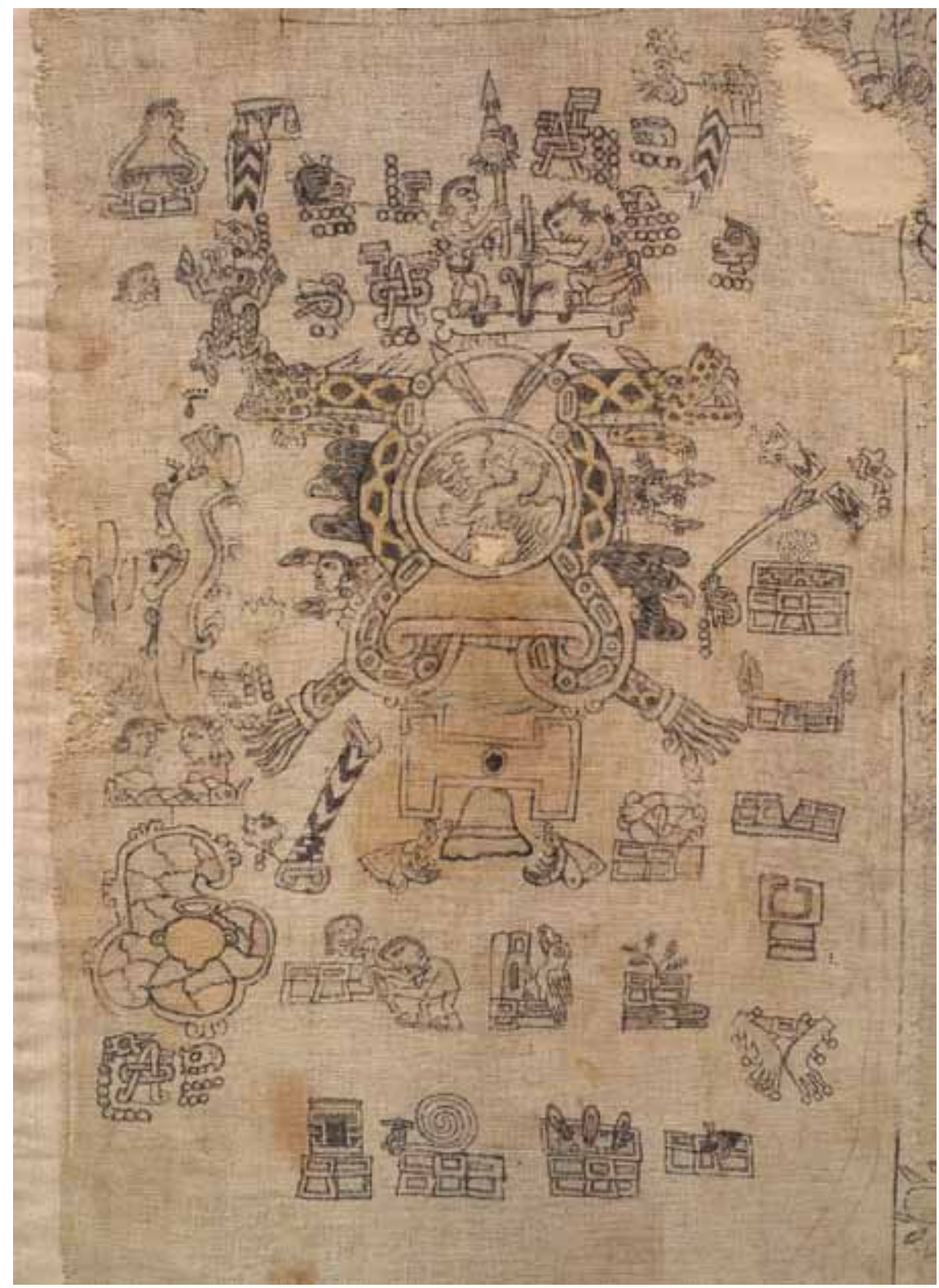

I. Lienzo de Tlapiltepec, topónimo en documento mixteco, fol. I. Royal Ontario Museum. 
una en el códice maya Dresdensis ${ }^{22}$ y otra de la región de la costa del Golfo (el Lienzo de San Juan Nayotla). ${ }^{23}$ Previamente, se consideraba posible un origen del Códice de Xalapa de esta misma zona, pero comprobé que resulta probable que su procedencia sea del estado de Morelos. ${ }^{24}$ Por último, es posible que existiera una representación en el Lienzo de Puácuaro de Michoacán, ${ }^{25}$ pero preferí no registrarla, en la ausencia de verificación personal, ${ }^{26}$ por lo cual este total queda quizá incompleto. Recientemente, logré documentar dos imágenes más del Lienzo Tepepelme III. ${ }^{27}$ Futuras investigaciones podrán proporcionar otros ejemplos, aunque dudo que sean lo suficientemente numerosos para modificar nuestro corpus.

\section{La repartición geográfica}

La repartición geográfica de esas representaciones proporciona información interesante (anexo I), al dejar de lado provisionalmente los ejemplos aislados de la costa del Golfo y del área maya, cuatro manuscritos del grupo Borgia incluyen II imágenes, entre las más complejas y elaboradas conforme a su origen prehispánico. Con sólo I4 manuscritos pictográficos, la región mixteca es la más rica, con un total de 76 ilustraciones. ${ }^{28}$ Los 36 manuscritos distintos del altiplano, lato sensu, sólo proporcionan 65, en su mayoría sencillas (salvo las del Borbónico, del Magliabechiano y del Tudela) ${ }^{29}$ Esta dispersión se justifica en parte por el significado de las representaciones, pues en la mayoría de los documentos nahuas, como el Códice Mendoza, la Matrícula de tributos o los Mapas de Cuaubtinchan, las canchas corresponden por lo general a topónimos.

22. Códice Dresdensis, eds. Ferdinand Anders y Helmut Deckert (Graz: Akademische Druckund Verlagsanstalt, 1975).

23. Glass, Catálogo de la Colección de códices.

24. Eric Taladoire, "Le Codex de Jalapa: mapa del juego de pelota", en The Mesoamerican Ballgame from 2000 BC till 2000 AD, eds. Ted J.J. Leyenaar, Gerard W. van Bussel et al. (Leiden, Brill: Rijksmuseum voor Volkenkunde, I99I), III-II8.

25. Carreón Blaine, Le Tzompantli.

26. Glass, Catálogo de la Colección de Códices.

27. Comunicación personal con Rincón Mautner, 2013.

28. Silvia Garza Tarazona, Análisis de la arquitectura representada en los códices mixtecos (México: Escuela Nacional de Antropología e Historia, 1970).

29. Nicholson y Quiñones Keber, "Ballcourt Images in Central Mexican Native Tradition Pictorial Manuscripts”, II9-I33. 
Cada grupo de manuscritos presenta variaciones significativas. La inmensa mayoría de los folios sólo incluye una cancha, o varias dispersas en un paisaje amplio y complejo, como los Mapas de Cuauhtinchan, lo que se justifica, tratándose de topónimos, de antropónimos o de sitios. Pero varios folios contienen imágenes dobles o múltiples. El ejemplo más elaborado es el Códice Vindobonensis (1974), donde los folios 3 y 44 tienen dos canchas cada uno, el folio 7, tres, el I7, cuatro, y el I9, hasta cinco. Por supuesto, eso corresponde principalmente al simbolismo de las ilustraciones, un tema al cual regresaremos después, pero se nota un patrón similar en otros documentos. En el Códice García Granados ${ }^{30}$ figuran dos canchas, en el Códice Laud también (1966), y hasta un grupo de cinco en el Mapa de Santo Tomás Ocotepeque. ${ }^{3 \mathrm{I}} \mathrm{Al}$ contrario, Sahagún, tanto en el Códice florentino (1950-1982) como en los Primeros memoriales, ${ }^{32}$ habla de dos canchas en el recinto sagrado de Tenochtitlan, el Teotlachco y el Tezcatlachco, pero sólo dibuja una. Finalmente, debemos mencionar el ejemplo discutible de la doble cancha en cruz del Mapa de Cuauhtinchan $2 .{ }^{33}$ Aunque pienso que sí se trata de dos campos perpendiculares, ${ }^{34}$ el motivo es muy inusual y exige un estudio a profundidad. ${ }^{35}$ La presencia de canchas múltiples en numerosos sitios arqueológicos está bien documentada, en Tula (tres) y Tula Chico (tres), Xochicalco (cinco), Cantona (24), El Tajín (17), Monte Albán (tres), Tikal (cinco) o Chichén Itzá (13). Este paralelismo de distribución, conforme a la realidad urbanística, no necesita forzosamente entonces una interpretación simbólica, aun si fuera válida en el caso preciso del Vindobonensis.

30. Barlow, "Los caciques precortesianos de Tlatelolco", 467-483.

31. Caso, "Los lienzos mixtecos de Ihuitlán", 237-274.

32. Primeros memoriales by Fray Bernardino de Sahagún, paleografía del texto náhuatl y traducción al inglés por Thelma D. Sullivan, completado y revisado con adiciones por Henry B. Nicholson, Arthur J. O. Anderson et al. (Norman: University of Oklahoma Press, 1997).

33. Bittman Simons, Los mapas de Cuaubtinchan y la Historia Tolteca-Chichimeca.

34. De acuerdo con Manuel Aguilar, comunicación personal, agosto de 2012.

35. En numerosos sitios, como Toniná, por ejemplo, existen canchas que tienen orientaciones perpendiculares. Tal vez el dibujo del Mapa de Cuauhtinchan 2 se refiere, de manera codificada, a este fenómeno. Recordemos también que las dos etapas sucesivas del Teotlachco de Tenochtitlan no tienen la misma orientación (Eduardo Matos Moctezuma, "The Ballcourt in Tenochtitlan", en The Sport of Life and Death, ed. Michael Whittington (Carolina del Norte: Mint Museum y Thames and Hudson, 200I), 88-96. 


\section{Análisis morfológico y arquitectónico}

Previo al análisis general, se necesita examinar detalladamente dos casos excepcionales. El primero corresponde a la imagen única del Códice Dresdensis 4Ia (1975). Se trata de la sola cancha registrada en los tres manuscritos mayas conocidos, con una representación en perfil o en corte. En ella, una espiral simboliza el agua, mientras la deidad Chac está sentada encima del juego de pelota. Aunque única, esta ilustración llama la atención en diversos aspectos. Primero, corresponde al modo usual de las representaciones mayas, o sea de perfil, lo que la diferencia mucho de las demás imágenes que la dibujan en planta. ${ }^{36}$ Segundo, la falta de canchas posclásicas en las tierras bajas mayas septentrionales de esta época siempre ha dejado perplejos a los arqueólogos. Pero el dibujo de una cancha aparece también como colgante del collar de uno de los personajes de los murales de Santa Rita (Quintana Roo), ${ }^{37}$ lo que comprueba que el juego no era completamente desconocido, si bien no se practicaba en espacios hechos de mampostería. Tercero, porque, a pesar de esas anomalías, la asociación de la cancha con el agua y la fertilidad agraria resulta coherente con el simbolismo de las otras imágenes, como lo veremos más adelante.

La imagen del Lienzo de San Juan Nayotla ${ }^{38}$ resulta de igual manera reveladora. La morfología en $\mathrm{H}$ de la cancha es similar a las del altiplano, pero el dibujo está compuesto de cuatro elementos rectangulares independientes, una morfología documentada en la región, ${ }^{39}$ así como, por ejemplo, en Chichén Itzá. Eso sugiere una correspondencia entre las representaciones pictográficas y los datos arqueológicos regionales, a pesar de la importante diferencia cronológica.

Salvo los dos ejemplos anteriores, todas las demás imágenes adoptan la forma de $\mathrm{H}$ o doble $\mathrm{T}$, que permite su identificación. En algunos casos específicos esta morfología resulta más bien evocada que efectiva. En el Nuttall (I5,

36. Taladoire, "Las representaciones bi y tri-dimensionales de juegos de pelota en Mesoamérica", Arqueología Mexicana, núm. II7 (2012): I8-27.

37. Corinne Jourdan, Santa Rita. Les peintures murales de la structure I: réajustement de leur appartenance culturelle et nouvelle approche iconographique. Mémoire de DEA (París: Université de Paris I, 1999).

38. Glass, Catálogo de la Colección de Códices.

39. Annick Daneeles, "Ballcourts and Politics in the Lower Cotaxtla Valley: a Model to Understand Classic Central Veracruz?", en Classic-period Cultural Currents in Southern and Central Veracruz, eds. Philip J. Arnold III y Christopher A. Pool, Pre-Columbian Studies (Washington: Dumbarton Oaks, 2008), 197-223. 
I7, I8, I9) y en el Bodley (2) sólo emerge de la boca de un cocodrilo o del cuerpo de un individuo una mitad de la cancha, aunque fácilmente identificable. Asimismo, en el Códice Azcatitlán, ${ }^{40}$ únicamente se distingue un lado de la cancha, el lado opuesto está ocupado o tapado por el cuerpo de un sacrificado. Esas modificaciones gráficas no impiden la lectura global del motivo como tlachco (cancha en idioma náhuatl).

Casi de manera sistemática, la cancha está delimitada por una doble línea, pero en I9 ejemplos se trata de una línea simple. Esos últimos están todos fechados en la época colonial. En ambos casos, la forma en I resulta bien marcada, lo que confirma su valor morfológico, pero, mientras sólo ésta esté presente en los documentos tardíos, la delineación doble debe tener un sentido. Posiblemente se refiere al carácter "hundido" de las canchas para evocar su aspecto de área cerrada. En unos dibujos los límites están definidos por líneas parciales, interrumpidas, como si el tlacuilo hubiera querido indicar posibles accesos o elementos arquitectónicos específicos (Códice en Cruz, Mapa Cozcatzin, ${ }^{4 \mathrm{I}}$ Códice de 20 mazorcas..$^{22} \mathrm{Al}$ contrario, seis dibujos procedentes de los códices Bodley (Io), Borbónico (27) y Borgia (35) están delimitados por líneas triples. En esas representaciones, la delineación externa está decorada con líneas de motivos redondos que se interpretan por lo general como estrellas. Este motivo figura también en algunos otros ejemplos (Nuttall I5). La línea externa tendría entonces una función simbólica, relacionada con el aspecto ritual, sin intervenir en la morfología arquitectónica.

De manera general, y principalmente en los documentos del altiplano, no se representan las estructuras laterales. Es sobre todo en los documentos mixtecos (Bodley, Nuttall, Selden y Vindobonensis) donde se encuentran elementos simbólicos como grecas, espigas o líneas inclinadas que las evocan. Parece más bien una convención gráfica que la búsqueda de una representación arquitectónica. En este contexto, dos ejemplos aislados merecen una mención específica. En el Códice Moctezuma ${ }^{43}$ formas piramidales simplificadas ocupan el lugar de las estructuras laterales, y en el Fejérváry-Mayer (197I) elementos sim-

40. Robert H. Barlow, "El Códice Azcatitlán", Journal de la Société des Américanistes, nouvelle série, vol. 38 (I949): IOI-I35.

4I. Eugène Boban, Documents pour servir à l'histoire du Mexique. Catalogue raisonné de la collection E. E. Goupil (París: Ernest Leroux, I89I).

42. Robert H. Barlow, "El palimpsesto de veinte mazorcas", Revista Mexicana de Estudios Antropológicos, vol. I7 (196I): 97-IIO.

43. Noguez, "Códice Moctezuma", 84-85. 
bólicos ocupan el lugar por lo común dedicado a los anillos. Existe obviamente el propósito de representar elementos arquitectónicos que se diferencian del todo de las esculturas.

En los dibujos del Códice florentino ${ }^{44}$ y de Durán ${ }^{45}$ las estructuras laterales de mampostería están representadas al estilo europeo, lo que no debe sorprendernos. Curiosamente, lo mismo ocurre en algunos dibujos coloniales, como el Lienzo de Ihuitlán ${ }^{46}$ y el Mapa de Metlatoyuca, ${ }^{47}$ donde la cancha está inscrita en un rectángulo. En el Mapa de Cuaubtinchan $3^{48}$ está trazada una verdadera construcción de mampostería. ¿Se justificarían esas imágenes por la iniciativa del tlacuilo? ¿Por influencias europeas? Esas diferencias menores no interfieren con la morfología básica en I o doble T, sino que hasta cierto punto confirman la posibilidad de la interpretación de las líneas dobles como indicio del carácter "hundido" de las canchas.

A manera de síntesis del aspecto morfológico, entonces, esas representaciones confirman y completan los datos arqueológicos: los sustentan por su morfología; los amplían por la cantidad de canchas asociadas al universo náhuatl, donde la mayoría de ellas han desaparecido, mientras se puede esbozar a partir de los documentos pictográficos un mapa de repartición. Curiosamente, salvo la cancha documentada por Muñoz Camargo, ${ }^{49}$ resulta sorprendente la falta de ellas en los documentos relativos al área de Cholula y de Tlaxcala.

\section{Elementos adicionales}

Pueden obtenerse de las representaciones dos tipos de informaciones complementarias sobre elementos arquitectónicos pertinentes: los anillos y el centro de las canchas. Los anillos sólo figuran en 26 de las canchas, casi todas del altiplano, salvo el Nuttall (74). De manera general, están dibujados en el lugar

44. Bernardino de Sahagún, Florentine Codex. General History of the Things of New Spain, trad. y ed. Arthur J.O. Anderson y Charles E. Dibble, I2 vols. (Santa Fe y Salt Lake City: The School of American Research and the University of Utah, 1950-1982).

45. Diego Durán, Historia de las Indias de Nueva España e Islas de Tierra Firme, 2 vols. (México: Porrúa, 1984).

46. Caso, "Los lienzos mixtecos de Ihuitlán".

47. Glass, Catálogo de la Colección de Códices.

48. Bittman Simons, Los mapas de Cuauhtinchan y la Historia Tolteca-Chichimeca.

49. Muñoz Camargo, Historia de Tlaxcala. 
apropiado, pero como si estuvieran fuera de la cancha, lo que se debe probablemente al tamaño reducido de las imágenes o a una convención pictográfica. Su posición encima de las estructuras laterales está ilustrada en los dibujos de Durán, ${ }^{50}$ de los Primeros memoriales ${ }^{51}$ y de algunos otros ejemplos. Fuera del altiplano, registramos la presencia de anillos o elementos circulares en las ilustraciones del Borgia (2I, 4O, 42), lo que corresponde a la procedencia de este manuscrito.$^{2}$ En este último caso, no son verdaderos anillos, sino elementos circulares de los cuales salen cabezas de serpientes. La presencia de anillos en un topónimo del Nuttall (74) sugiere que el sitio al cual se refiere se ubicaría fuera del territorio mixteco, tal vez en una área relacionada con el mismo grupo Borgia. De hecho, ningún ejemplo de anillo arqueológico procede de la zona de Oaxaca, ${ }^{53}$ mientras son relativamente frecuentes en el altiplano. ${ }^{54}$ La presencia de anillos en las canchas no es un fenómeno generalizado, sino más bien excepcional, lo que explica su ausencia en muchos sitios.55

A diferencia de los anillos, los motivos que designan el centro de las canchas, aunque muy variados, corresponden a todos los tipos de manuscritos y de procedencia..$^{56}$ Tenemos registrados 23 ejemplos de motivos centrales, en los tres conjuntos de códices. Hay que distinguirlos de las escasas posibles pelotas representadas en otras partes de las canchas, y a veces fuera de ellas (Aubin 19). El centro está generalmente indicado por un círculo sencillo, pero en varias ocasiones otros elementos lo ocupan: un posible signo ollin compuesto de los cuerpos de dos serpientes entrelazados en el Borbónico 27, una espiral en el Dres-

50. Durán, Historia de las Indias de Nueva España.

5I. Sahagún, Primeros memoriales.

52. Bodo Spranz, Los dioses en los códices mexicanos del grupo Borgia: una investigación iconográfica (México: Fondo de Cultura Económica, 1973).

53. Ramzy Barrois, "Les Sculptures associées aux jeux de balle dans l'aire mésoaméricaine", tesis doctoral (París: Université de Paris I, 2006).

54. En la última publicación de Roberto Rochín, Felipe Solís Olguín y Roberto Velasco (Ulama. El juego de la vida y la muerte. The Game of life and Death [México: Estado de Sinaloa/Universidad Autónoma de Sinaloa], 20Io) se ve una foto de la cancha de Yagul con anillos, pero se trata de una reconstitución, ya que no se encontró este tipo de esculturas en las excavaciones. Charles R. Wicke, "The Ball Court at Yagul, Oaxaca: a Comparative Study", Mesoamerican Notes, núm. 5 (1957): 37-76.

55. Felipe Solís Olguín, "Estudio de los anillos de juego de pelota: el origen de este elemento", en Actas del XLI Congreso Internacional de Americanistas (México: Instituto Nacional de Antropología e Historia, 1975): 252-26r.

56. Eric Taladoire, "El centro de Tlachco, ¿el centro del mundo?", Anales de Antropología 49, núm. I (2015): I57-I8I. 


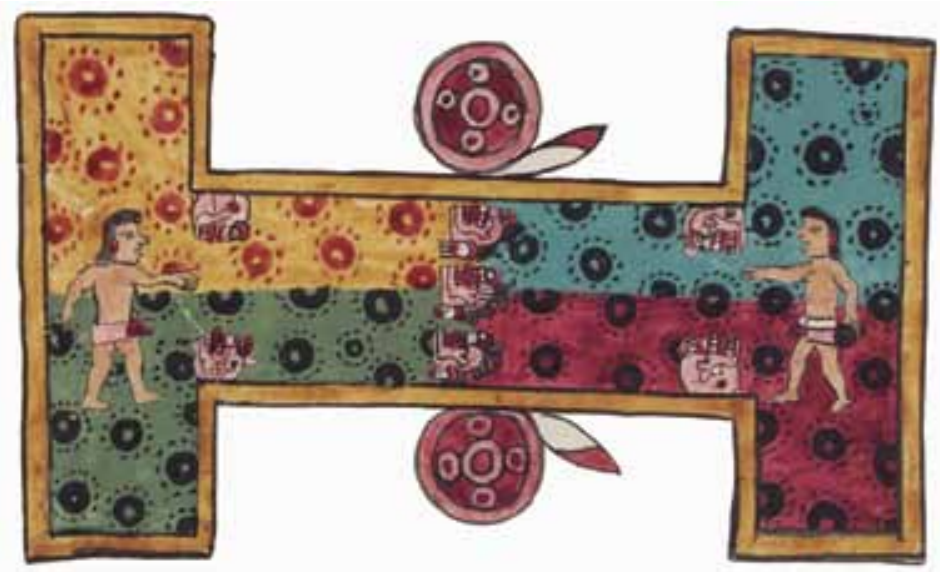

2. Códice Tudela, fol. 67r. Un alineamiento de cráneos indica el eje transversal de la cancha entre los dos anillos. Museo de América.

densis 4Ia (1975), un cráneo (en una línea de tres) en el Magliabechiano y en el Tudela (fig. 2), un cráneo sangriento en el Borbónico 19, un círculo inscrito en el cuerpo de una deidad en el Borgia (35) y un chalchihuitl en el Nuttall (74). En el Borgia (2I y 42), la víctima de un sacrificio ocupa el mismo lugar. Vale la pena, al respecto, señalar que la insistencia sobre el centro no impide la presencia de anillos, en el Borbónico (27) o en el Nuttall (74). La diversidad de identificaciones del centro confirma, por un lado, su importancia, y por otro, su valor simbólico más que morfológico o arquitectónico. En este contexto podemos adelantar una hipótesis: en el Mendoza (2I) y en la Matrícula de tributos (3, 5) la cancha misma está inscrita en un círculo. Aunque muy probablemente, tratándose de topónimos, esta representación corresponde al nombre de una ciudad (en el círculo o en lo redondo del juego de pelota), no podemos descartar una interpretación simbólica complementaria de la cancha misma como centro.

Existen otras maneras de subrayar la importancia del centro. En efecto, en 58 ocurrencias, las canchas están divididas en cuatro cuadrantes por líneas perpendiculares que se cruzan en el centro. En algunos otros ejemplos, una sola línea divide la cancha en dos mitades, sea transversal, sea longitudinalmente (Borbónico 19, Laud 40). Los alineamientos de cráneos en las canchas del Tudela (fig. 2) o del Magliabechiano tienen un papel similar. Existe un solo ejemplo (Aubin 19) de una subdivisión en ocho cuadrantes. Sin considerar, por ahora, la repartición de los colores en los cuadrantes, esas subdivisiones también defi- 
nen el centro. Aunque, respecto a la técnica, las líneas transversales confirman hasta cierto punto la probable repartición de los jugadores en las canchas, su ausencia en el Borbónico (27) o en el Borgia (42), donde obviamente se enfrentan deidades y jugadores, sugiere que no son necesarias para jugar. La presencia física de las líneas no constituye entonces un rasgo directamente asociado al juego ni es un elemento arquitectónico. Su función básica correspondería a consideraciones rituales o para confirmar la importancia del centro.

\section{¿El simbolismo de los colores?}

La división de muchas canchas en cuadrantes está reforzada por la inclusión de colores. La importancia y el simbolismo de los colores en el mundo prehispánico es un tema bien documentado, aunque controvertido. No hay que sorprenderse si varios investigadores como Krickeberg 57 y Seler ${ }^{58}$ han tratado de interpretar su repartición en las canchas en términos simbólicos. Pero, al mismo tiempo, debemos ser prudentes. Como lo demostró Diana Magaloni ${ }^{59}$ a propósito del Códice florentino, no sólo los colores, sino también sus variaciones, sus tonos y sus materiales pictóricos deben tomarse en consideración. El rojo no es simplemente rojo, sino claro, oscuro, rosado, bermellón, entre otros y puede obtenerse de distintas materias primas, con significados diferentes. En este sentido, el estudio detallado de cada imagen resulta primordial para interpretar las implicaciones.

Considerando lo anterior, sólo queremos aquí proponer observaciones preliminares. De las I57 imágenes, 6I son blancas o grises, o les falta el color. La inmensa mayoría de esas representaciones procede de manuscritos coloniales o al estilo europeo, ${ }^{60}$ pero existen algunos ejemplos de canchas sin color en códices prehispánicos como el Laud o el Selden. La falta de cromatismo no

57. Walter Krickeberg, "El juego de pelota mesoamericano y su simbolismo religioso", en Paul Kirchhoff, Traducciones mesoamericanistas I (México: Sociedad Mexicana de Antropología, 1966), I9I-313.

58. Eduard Seler, Gesammelte Abhandlungen zur Amerikanischen Sprach- und Altertumskunde, 5 vols. (Berlín: Akademische Druck- und Verlagsanstalt, 1902-1923).

59. Diana Magaloni Kerpel, Los colores del Nuevo Mundo. Arhstos, materiales y la creación del Códice florentino (México: Universidad Nacional Autónoma de México/The Getty Research Institute, 20I4).

6o. Véase Durán, Historia de las Indias de Nueva España; y Sahagún, Primeros memoriales. 
resulta entonces de una simplificación tardía de los dibujos, sino que, antes de la Conquista, no afectaba su valor simbólico. Unas 25 canchas son monocromas, con principalmente el uso del rojo (is casos), pero también del azul (Nuttall 67), del negro o del amarillo (Telleriano-Remensis). Otros 22 ejemplos combinan dos colores, rojo casi siempre para una mitad de la cancha, y para la otra mitad, verde, azul o amarillo. En una perspectiva ligeramente diferente, los folios 3 y 44 del Vindobonensis mezclan dos representaciones: cada cancha es monocroma, pero alterna un tlachco rojo con otro negro.

Son escasas, entonces, las imágenes que combinan cuatro colores, con sólo 27 ocurrencias, principalmente de los códices mixtecos y del grupo Borgia. Entre los colores figuran el rojo y verde o azul, pero también amarillo, café, blanco y negro. Un examen sistemático no permitió registrar una disposición recurrente de los colores, conforme, por ejemplo, a las direcciones cardinales. El rojo puede ubicarse entre el azul, el verde o el amarillo (anexo 5). Sólo nueve ejemplos demuestran lo que podría corresponder a un patrón: la sucesión rojo-verde-amarillo-azul, pero la ubicación de los colores cambia de una cancha a otra. Eso no impide una interpretación del todo de tipo astronómico que resultaría específica de cada representación. A pesar de las hipótesis de Seler ${ }^{61}$ y Krickeberg, ${ }^{62}$ es imposible entonces identificar un patrón significativo de orientación astronómica. Respecto a las canchas mismas, en el contexto arqueológico, resulta asimismo imposible la identificación de orientaciones preferenciales. Es significativa, además, la falta global de referencias específicas, entre los arqueoastrónomos más conocidos (Aveni, Sprajc), al tema del simbolismo astronómico del juego de pelota, salvo en el contexto urbano de algunos sitios. ${ }^{63}$

Aún, podemos registrar ciertas predominancias. Entre las 96 canchas coloreadas, el rojo está presente por lo menos en 68 casos, lo que le confiere un alto valor simbólico en relación con el juego. El rojo esta comúnmente asociado al este, al sol naciente, a la fertilidad agraria, a la vegetación y a la sangre del sacrificio. El verde y el azul, con más de 30 ocurrencias, evocan el sur, la luz, el fuego. Parecen entonces existir unas constantes, tanto en colores dominantes, como en sus asociaciones recurrentes. Si resulta imposible sacar con-

6I. Seler, Gesammelte Abhandlungen.

62. Krickeberg, "El juego de pelota mesoamericano".

63. Taladoire, "Cinco tesis relativas al juego de pelota", Arqueología. Revista de la Coordinación de Arqueología del INAH, en prensa. 
clusiones significativas de la disposición interna de los colores, por lo menos su presencia y sus asociaciones corresponden al simbolismo intrínseco de una gran proporción de las imágenes, un tema al cual regresaremos más adelante.

\section{Las funciones de las representaciones}

En síntesis, hemos definido cuatro funciones distintas, aunque no exclusivas: el tlachco como cancha, como topónimo, como antropónimo y con valor ritual y simbólico. No son exclusivas, porque el tlachco, como área de juego, puede ser al mismo tiempo un topónimo o el marco arquitectónico de un ritual, como en el Borbónico (27) o el Borgia (2I). Asimismo, en el Vindobonensis (3, 44), el uso de la cancha como topónimo no contradice su significado simbólico, ilustrado por los distintos colores. Normalmente, no deberían existir interferencias entre los topónimos y los antropónimos, pero no se puede descartar la hipótesis de un dirigente llevando en su nombre el término tlachco, haciendo referencia a una conquista o a la presencia de una cancha importante en su reino. El número de funciones identificadas sobrepasa entonces las ocurrencias registradas.

La primera función corresponde entonces a la cancha como marco arquitectónico donde se desarrolla el juego, con I4 ejemplos. Por supuesto, caben en esta rúbrica las representaciones de los cronistas como Sahagún, Durán, Muñoz Camargo y varios documentos coloniales donde la cancha es un elemento de identificación topográfica. ${ }^{64}$ También podemos mencionar la Historia Tolteca-Chichimeca (1937), el Códice Xolotl, en relación con el juego practicado por Nezahualcóyotl, previo a la llegada de los emisarios de Maxtlatl, ${ }^{65}$ el Nuttall 8o, el Magliabechiano, el Laud (40) o el Borbónico (27). En esos últimos casos, aunque el contenido del folio es ritual o simbólico, los dioses o los dirigentes están jugando conforme al carácter religioso y político del tlachtli.

La gran mayoría de las representaciones, con más de Ioo ocurrencias, incluyendo los ejemplos de canchas múltiples como el Lienzo de Santo Tomás Ocotepeque, los folios del Vindobonensis o los Mapas de Cuaubtinchan, corres-

64. Luis Alberto Martos y Salvador Pulido Méndez, "Un juego de pelota en la ciudad de México", Arqueología. Revista de la Coordinación de Arqueología del INAH, segunda época I (1989); Eric Taladoire, "Le Codex de Jalapa, ou mapa del juego de pelota".

65. Charles Dibble, Códice Xolotl (Salt Lake City y México: University of Utah y Universidad Nacional Autónoma de México, 195I). 
3. Códice Mendoza, topónimo de Tlachco, Bodleian Library, MS.Arch. Selden, A.I, fol. 3I.

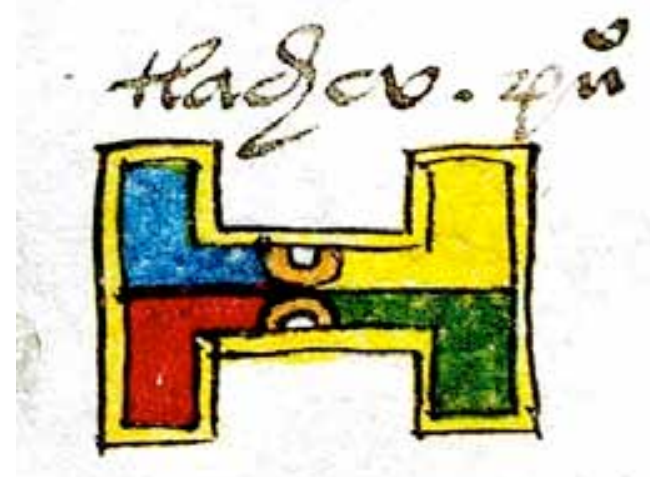

ponden a topónimos. ${ }^{66}$ Entre los sitios identificados figuran Tlachco (Taxco) en el Códice Mendoza (3I) (fig. 3), Tlachco (Querétaro), Tlachapa, Tlachuacalco, Zacatlachco, Tlachmalacac, Tlachyahualpa o Tlachyahualco, Tlachquiauhco, Tlalachco, Tlachtitlan y Tlaxiaco (anexo 2). En los manuscritos mixtecos, unos sitios identificados por $\mathrm{Caso}^{67}$ y $\mathrm{Smith}^{68}$ serían Lugar del juego de la noche o Río del juego de pelota, lo que no implica forzosamente una transcripción lingüística. También en los manuscritos nahuas, el tlachco permite a veces la identificación de un lugar donde no aparece el término, como en el caso de Arroyo de Zapote. ${ }^{69}$

Mientras algunos sitios resultan bien identificados (Taxco, Querétaro, Tlaxiaco, Tlachapa en Hidalgo y Tlalachco cerca de Teotenango), numerosos topónimos quedan todavía por ubicarse..$^{70} \mathrm{~A}$ veces, el topónimo sólo proporciona una identificación general, como en el caso del Nuttall (45), para sitios de la provincia de Tututepec. Además, el mismo topónimo puede por supuesto

66. Antonio Peñafiel, Nombres geográficos de México: catálogo alfabético de los nombres y lugares pertenecientes al idioma náhuatl. Estudio jeroglifico de la Matrícula de tributos del Códice Mendocino (Guadalajara: E. Avina Levy, 1967); César Macazaga Ordoño, Nombres geográficos de México (México: Innovación, 1980).

67. Alfonso Caso, Interpretación del Códice Bodley 2858 (México: Sociedad Mexicana de Antropología, 1964); Caso "Los lienzos mixtecos de Ihuitlán”; Interpretación del Códice Selden; mapa de Santo Tomás Ocotepeque.

68. Mary Elizabeth Smith, Picture Writing from Ancient Southern Mexico: Mixtec Place Signs and Maps (Norman: University of Oklahoma Press, 1973).

69. Roberto Weitlaner y Carlo Antonio Castro, "Lienzo de Tlacoatzintepec", Yan, núm. 2 (I953): I09-II4.

70. Nicholson y Quiñones Keber, Ballcourt Images. 
leerse y pronunciarse de manera diferente según el origen, nahua o mixteco, del manuscrito, como sería el caso de la imagen del Nuttall (74).

Finalmente, es relevante insistir sobre el doble sentido de varias representaciones. Las figuraciones múltiples del Vindobonensis reflejan esta ambigüedad. La presencia de varias canchas asociadas en el glifo tepetl asegura su valor topográfico y su probable valor toponímico, ${ }^{7 \mathrm{I}}$ pero, al mismo tiempo, no podemos negar su sentido simbólico como alusión a la puesta o la salida del sol. La coexistencia de una cancha negra y de otra roja es un indicio de la dualidad luz/oscuridad, que no se refleja en la toponimia.

De las 2I ocurrencias de tlachco como antropónimo, sólo una proviene de manuscritos del altiplano, o sea Tlachcuyotl, en el Mapa Cozcatzin y en el Título de Tierra Santa Isabel Tola, las demás proceden de los manuscritos mixtecos. Los desciframientos de $\mathrm{Caso}^{72}$ identificaron dirigentes y personajes históricos como in Agua Humeante Tlachco o I3 Viento Tlachco de Guerra. Aunque esos manuscritos tratan de asuntos genealógicos cada nombre es personal e intransmisible. ¿En qué medida, como hemos mencionado antes, podemos descartar la hipótesis del uso de esos nombres referentes a una conquista o a la presencia en su reino de una cancha famosa? Eso justificaría parcialmente esta especificidad funcional, casi exclusiva de la Mixteca, pero ¿por qué no existe el mismo fenómeno en el altiplano?

\section{Una función transversal: el simbolismo}

Llegamos por último a la función ritual o religiosa con por lo menos 2I ocurrencias seguras, sin olvidar las funciones duales ya mencionadas. En varios manuscritos prehispánicos la cancha sirve en efecto para el juego, donde se enfrentan deidades o encarnaciones de entidades sobrenaturales. En el Borgia (2I), el Tezcatlipoca rojo arrostra el Tezcatlipoca negro, ambos rodeados de múltiples símbolos de sacrificio (cráneos, corazones, hueso, serpientes). Según Olivier, ${ }^{73}$ el color negro es, por esencia, símbolo de Tezcatlipoca, el rojo per-

71. Smith, Picture Writing from Ancient Southern Mexico.

72. Caso, Interpretación del Códice Bodley; "Los lienzos mixtecos de Ihuitlán”; Interpretación del Códice Selden; "Mapa de Santo Tomás Ocotepeque”; Alfonso Caso, Interpretación del Códice Colombino (México: Sociedad Mexicana de Antropología, 1966).

73. Guilhem Olivier, Moqueries et métamorphoses d’un dieu aztèque. Tezcatlipoca, le "seigneur au miroir fumant" (París: Institut d'Ethnologie, 1997). 


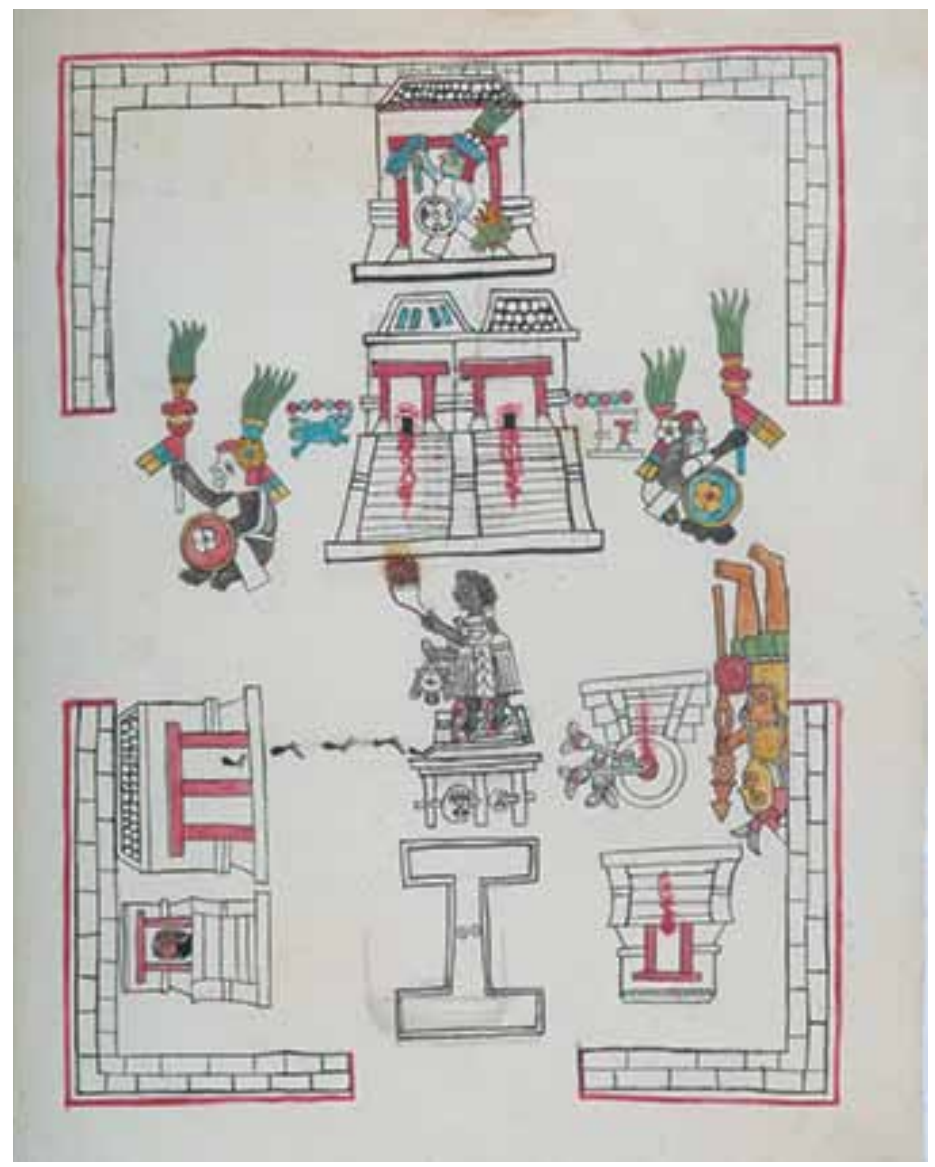

4. Bernardino de Sahagún, Primeros memoriales, fol. 269r. Representación del recinto sagrado de Tenochtitlan, con ubicación de la cancha, cerca del tzompantli. Biblioteca Real, Madrid. (C) Patrimonio Nacional.

mite asociarlo con Xipe Totec y el renacimiento vegetal. Recordamos aquí que la misma yuxtaposición de colores define las canchas dobles del Vindobonensis $(3,44)$. En el Borbónico (27), están jugando Ixtlilton, Centéotl, Cihuacóatl y Ehécatl, deidades principalmente asociadas al mundo vegetal, al maíz, a la lluvia y a la fertilidad. En el Dresdensis (4ra) (1975), Chac está sentado encima de la cancha. En el Borgia (40) Quetzalcóatl y Yohualtecuhtli se enfrentan de cada lado de Tonacatecuhtli, mientras en el folio 35, Tezcatlipoca y Tlazoltéotl 
parecen contemplar una escena de parto. Los dioses asociados al juego pertenecen casi todos al complejo divino definido por Nicholson ${ }^{74}$ como lluviahumedad-fertilidad agraria (rain-moisture-agricultural fertility). Los motivos y elementos asociados a este complejo incluyen naturalmente la lluvia, el agua, el parto, el maguey y el pulque, los malacates, los colores verde y rojo, y animales como el coyote, el cocodrilo, entre otros, un aspecto al cual regresaremos más adelante.

Los jugadores de los códices mixtecos son más bien dirigentes. En el Bodley (Io), se trata de 3 Ollin y 8 Venado, este último lleva una máscara de cráneo. En el Colombino (II), nuevamente 8 Venado juega contra 6 Jaguar. Finalmente tanto en el Nuttall (2I) como en el Borgia (42) encontramos a Quetzalcóatl, bajo la forma de 9 Viento. A diferencia de los documentos del altiplano, salvo la Tlazoltéotl del Borgia (35), registramos en los códices mixtecos la presencia de algunas mujeres o deidades femeninas, entre ellas II Serpiente, por lo general asociada a Xochiquetzal. No participan en el juego, sino figuradas al lado de las canchas. Todos los cronistas coinciden en afirmar que las mujeres no jugaban; su presencia se justifica más bien por su pertenencia al complejo de deidades agrarias, en relación con la fertilidad, lo que recuerda la escena de parto del Códice Borgia. Unas mujeres parecen presenciar el juego en el panel hace poco encontrado en Quiriguá.75 María Isabel Ramos ${ }^{76}$ se dedicó recientemente al estudio de la relación entre las mujeres y el juego, pero salvo un caso excepcional de una jugadora de Sinaloa, la participación femenina se limita a presenciar el juego o a organizar las actividades complementarias como las comidas.

Esas diferencias reflejan en parte la repartición geográfica de procedencia de los manuscritos y su carácter ritual o histórico, pero no contradicen la asociación de individuos con deidades, como 9 Viento con Quetzalcóatl u II Serpiente con Xochiquetzal. Los dioses y los individuos se relacionan casi en exclusiva con el complejo asociado al mundo vegetal, a la fertilidad agraria, a la tierra, a la lluvia y al agua. El tlachco está principalmente asociado al con-

74. Henry B. Nicholson, "Religion in Pre-Hispanic Central Mexico", en Handbook of Middle American Indians, eds. Gordon F. Ekholm e Ignacio Bernal, vol. ıo (Austin: University of Texas Press, 197I), 395-446.

75. José Crasborn Chavarría, "Informe del hallazgo de la banca y panel de la estructura IB-I4 del parque arqueológico Quiriguá. Ministerio de Cultura y Deportes, Guatemala", 201 I.

76. Citada en Ulama: The Survival of the Pre-Columbian Ballgame, ed. Manuel Aguilar, en prensa; véase también Manuel Aguilar Moreno, "Ulama: pasado, presente y futuro del juego de pelota mesoamericano", en Anales de Antropología (2015): 73-II2. 
junto cosmogónico de lluvia-humedad-fertilidad agraria y, en consecuencia, al parto, al sacrificio, a la muerte y a la fertilidad en general.

Esos últimos temas están presentes en los mismos manuscritos, en estrecha relación con los anteriores. En los códices Aubin (19) y Borbónico (19), cuyas imágenes son casi similares, yace un cuerpo decapitado al lado de la cancha, mientras en el Azcatitlán, un sacrificado por cardiectomía oculta la mitad de la cancha. En los códices Magliabechiano y Tudela también hay representaciones similares, dos jugadores se enfrentan en una cancha donde tres cráneos simbolizan la línea transversal central. Cuatro cráneos más decoran cada esquina de la cancha. Se ha privilegiado la hipótesis de una asociación entre el juego y la decapitación en el marco de los ritos agrícolas. Aun así, el sacrificio por cardiectomía se ha ilustrado frecuentemente en los manuscritos (Borgia 2I, Nuttall 2I, 44, Rollo Selden), sin que podamos, por el momento, interpretar esa diferencia. La asociación del juego y del sacrificio, por decapitación o por cardiectomía, está bien documentada en la iconografía de los sitios de Chichén Itzá, Aparicio, El Tajín, aun si el tema de la decapitación resulta más común.

El tema del parto está mucho menos documentado, y sólo tenemos, aparentemente, el folio 35 del Códice Borgia; representa a Tezcatlipoca y Tlazoltéotl contemplando una escena de parto, en la cual el personaje central, vestido con la piel de un cocodrilo (un símbolo terrestre) está en posición de parturiente. La cancha está rodeada de estrellas que figuran el cielo nocturno. Podemos comparar esta escena con las ilustraciones que se encuentran tanto en el Nuttall (15, 17, 18, 19) como en el Vindobonensis (7, 19). En el primer caso, la mitad de una cancha, a veces rodeada de estrellas, sale de la boca de lo que es quizá también un cocodrilo. ${ }^{77}$ Aunque resulta difícil afirmar si el cocodrilo está comiendo la cancha o si ésta emerge de su boca, favorecemos la última interpretación, en comparación con el parto del Borgia 35. La serie de escenas complejas del Vindobonensis representa varias canchas en una sucesión cronológica. Las canchas inferiores son por lo general negras u oscuras, evocan la noche, la tierra, el sol nocturno. Las otras son rojas, adornadas con cabezas de quetzales y llamas, el símbolo de la luz, del cielo y del sol diurno. Por último, en los folios 7 y I9, la cancha superior comporta una grieta, de la cual sale, como lo indican los motivos de pies, una bola de hule humeante que podría simbolizar el sol renaciente, saliendo del inframundo. Esta apertura se ubica de hecho en el centro de la cancha, lo que nos recuerda el valor simbólico de 
este elemento, el Itzompan de Huitzilopochtli. $7^{7}$ Ambos conjuntos de imágenes pueden compararse con la escena de parto del Borgia. El tlachco o mejor dicho el centro del tlachco es el punto de salida del sol y del renacimiento vegetal. Esa hipótesis de una relación ritual y simbólica entre el tlachco, y más precisamente el centro, el parto, el sacrificio, el ciclo solar cotidiano y anual, el ciclo de la vegetación coincide con el complejo que Nicholson ${ }^{79}$ identifica como lluviahumedad-fertilidad agraria.

\section{Asociaciones recurrentes}

Todas las representaciones de canchas están incluidas en folios donde abundan los motivos, los símbolos y los pictogramas: ya hemos mencionado algunos. Sólo un estudio detallado de cada folio, en su contexto específico, permite definir el simbolismo completo de una imagen y de sus asociaciones. Este tipo de estudio no cabe en nuestras preocupaciones presentes. Sólo queremos insistir aquí sobre las asociaciones directas o recurrentes para definir una temática. Se identificaron 36 motivos o signos que se pueden clasificar en ocho rúbricas distintas (anexo 3).

Curiosamente, tres categorías de motivos sólo presentan asociaciones casuales, mientras se nota cierta coherencia en las otras cinco. De manera curiosa, porque si las dos primeras resultan circunstanciales, la tercera debería aparecer más sistemáticamente. Como anécdota, en algunos documentos coloniales, el tlachco, como topónimo, está asociado con una corona (Osuna), con cruces (Tlacoatzintepec) o con caminos (Mapa de Cuaubtinchan 2, Vindobonensis I3). Tratándose de topónimos, esas asociaciones tienen su sentido propio, sin otro valor que documental. En lo básico, lo mismo vale para las I2 imágenes donde la cancha está inscrita en un cerro (tepetl), lo que corresponde a su función de topónimos. ${ }^{80}$

Al contrario, se nota la escasez de motivos como las pelotas o el signo ollin. Sólo existen ocho ocurrencias de posibles pelotas, en la cancha, en las manos de los jugadores, a veces al lado del tlachco, aun si Hellmuth ${ }^{81}$ recuenta otros ejemplos más discutibles. Resultaría normal, por lo menos en nuestro modo de pensar,

78. Fernando Alvarado Tezozómoc, Crónica mexicana (México: Biblioteca Mexicana, 1878).

79. Nicholson, "Religion in Pre-Hispanic Central Mexico".

8o. Smith, Picture Writing from Ancient Southern Mexico.

8I. Hellmuth, "Notes on the Ballcourts Pictured". 
la presencia de pelotas en escenas de juego. Tal vez serían motivos redundantes y por esta razón inútiles. Parece más extraña la casi ausencia del glifo ollin, sólo representado, si no me equivoco, en el Borbónico (27), aunque de manera simbólica, y en el antropónimo del Bodley (Io). La literatura arqueológica asocia por tradición el glifo ollin al simbolismo del juego. ${ }^{82}$ La relación entre ollin y el tlachtli conformaba la interpretación antigua del juego como símbolo astronómico, en relación con el ciclo solar y astral. ${ }^{83}$ Aun si se registraron algunas evidencias arqueológicas de tal asociación, en El Tajín por ejemplo, ${ }^{84}$ esta escasez plantea una duda sobre la relación efectiva que todos (incluido el autor de esas líneas) afirmaron hasta ahora.

Tres categorías de motivos resultan al contrario muy abundantes y quizá complementarias. La primera reúne los símbolos relacionados con el sacrificio, sea por decapitación o por cardiectomía. Incluye I2 escenas de sacrificio, a las cuales se suman seis representaciones de cráneos (Tudela, Magliabechiano), el tzompantli de los Primeros memoriales (fig. 4), ${ }^{85}$ dos cuchillos sacrificiales (Nuttall 67, Tudela), huesos, esqueletos y corazones humanos (Borbónico 27, Borgia 2I). La relación del sacrificio con el juego queda sistemáticamente comprobada, hasta figurar en las mismas canchas. No sólo se trata de sacrificios humanos, sino también animales, como el de un jaguar en el Nuttall 44. Esta relación encuentra numerosos paralelismos en la iconografía de los sitios de Chichén Itzá, Aparicio, El Tajín, y en la arqueología, aun si, por lo general, la decapitación se manifiesta de manera más frecuente. Son relativamente frecuentes los ejemplos de cráneos (humanos o en esculturas) en escondites en el centro de las canchas, como en Santa Rosa (Chiapas), ${ }^{86}$ Paquimé ${ }^{87}$ o Cobá. ${ }^{88}$ Hasta en la época colonial se ofreció la cabeza de un caballo en una cancha de

82. Krickeberg, "El juego de pelota mesoamericano y su simbolismo religioso", I9I-313.

83. Krickeberg, "El juego de pelota mesoamericano y su simbolismo religioso", I9I-313.

84. Patricia Castillo Peña, La expresión simbólica del Tajín, Colección Científica, 306 (México: Instituto Nacional de Antropología e Historia, 1995).

85. Sahagún, Primeros memoriales, 1997.

86. Alejandro Martínez Muriel y Emilie Carreón Blaine, "El cráneo de Santa Rosa, Chiapas”, Arqueología. Revista de la Coordinación Nacional de Arqueología del INAH, núm. 4I (2009): 9-93.

87. Charles Di Peso, John B. Rinaldo et al., Casas Grandes: A Fallen Trading Center of the Gran Chichimeca, 8 vols. (Dragoon y Flagstaff, Arizona: Amerind Foundation/Northland Press).

88. María José Cón Uribe, “El juego de pelota en Cobá, Quintana Roo”, Arqueología, Revista de la Coordinación Nacional de Arqueología del INAH, núm. 23 (2000): 27-50. 
Kaminaljuyú, en Guatemala. ${ }^{89}$ La estrecha relación entre el juego y el sacrificio es un tema bien documentado que no se necesita desarrollar, salvo para insistir sobre la importancia de la cardiectomía en los manuscritos.

En las otras dos categorías de motivos se registraron respectivamente i8 y 30 veces (anexo 3). Una incluye figuras de guerreros en la cancha o en su vecindad (seis ejemplos), de armas (uno), de glifos de conquista (cuatro), de fuego y de llamas (en el Vindobonensis sobre todo). Estoy consciente del carácter en apariencia ecléctico de este agrupamiento. Se pueden interpretar las llamas de muchas otras maneras, como símbolos de luz, del sol naciente. Pero quise contrastar esta categoría con otra que reúne los símbolos relacionados con el agua, la tierra, la fertilidad. Encontré en las ilustraciones numerosas referencias a la lluvia (II ocurrencias), a ríos o flujos de agua (cinco), a la tierra (dos), a las plantas (una), las piedras verdes y especialmente al chalchihuitl (tres), a las plumas (dos), al maguey y al pulque (tres). Se pueden también incluir en este grupo los malacates (cinco ejemplos con el topónimo tlachmalacatl) alusivos a la mujer e indirectamente a la fertilidad. El cocodrilo, símbolo terrestre, pertenece al mismo conjunto. Esta categoría simboliza lo precioso, la fertilidad agraria, la tierra, el mundo nocturno, húmedo, femenino y de manera indirecta (con el maguey) el sacrificio. Esta temática está muy bien evidenciada en la iconografía relacionada con el juego. Las plantas brotan del cuello de los decapitados, el maguey y el pulque están presentes en los bajorrelieves del Tajín..$^{\circ}$

Presenciamos entonces dos categorías de motivos opuestos y complementarios, ambas relacionadas con el tlachtli y el sacrificio, pero no exclusivas. El Telleriano Remensis (42) representa un guerrero arriba de una cancha decorada con un motivo de lluvia. La relación de ambos temas con el tlachtli está documentada en la arqueología y la iconografía. Cada uno forma parte del concepto de la dualidad prehispánica: seco/húmedo, fuego/agua, masculino/ femenino, luz/oscuridad, guerra/agricultura, sequía/temporada de lluvias. Su abundancia respectiva expresa el simbolismo intrínseco del juego. Sólo quería subrayar esta complementariedad, que encuentra además cierta resonancia en los dos últimos temas ilustrados por los símbolos asociados. El primero abarca las representaciones animales, con un número reducido, pero significativo de especies: el águila y el quetzal, el jaguar y el coyote, la serpiente, el lagarto y el cocodrilo. El cocodrilo es un símbolo acuático y terrestre, el monstruo

89. Taladoire, Les Terrains de jeu de balle y "El centro de Tlachco".

90. Castillo Peña, La expresión simbólica del Tajin. 
terrestre en el agua original. El jaguar y el coyote están estrechamente ligados a la tierra, a la noche, pero también a la guerra. El águila y el quetzal figuran el mundo diurno, celeste, seco y guerrero. Volvemos a encontrar de nuevo los temas de la tierra y del agua, la noche y la luz, la fertilidad agraria y la guerra. La última categoría de motivos incluye las estrellas (el cielo nocturno), pero tal vez también los dispositivos de observación astronómica del Selden (5).9I A pesar de la gran diversidad temática de los motivos asociados, que hemos simplificado de manera deliberada con los riesgos intrínsecos de toda clasificación, su convergencia permite definir cinco interpretaciones fundamentales: la relación entre el juego, la cancha y el sacrificio; el tlachco como símbolo de fertilidad, de donde brotan el agua y las plantas, a partir del sacrificio; el tlachco como símbolo del inframundo, de donde nacen el sol y la luz; la cancha como lugar de enfrentamiento entre fuerzas opuestas y complementarias; el tlachco como oposición luz/oscuridad, tierra/cielo, guerra/fertilidad agraria.

Salvo unos ejemplos aislados, y a pesar de su aparente diversidad, los motivos asociados a las representaciones de canchas conforman entonces un complejo muy homogéneo, coherente con el concepto de la dualidad prehispánica. Esta coherencia se hace eco del simbolismo de los colores, y del complejo de las deidades (anexo 4).

\section{A manera de sintesis}

En el transcurso de esta presentación, enfocamos nuestra atención en un tema específico, de los tlachcos en los códices, relativamente bien conocido, pero pocas veces estudiado de manera sistemática. ${ }^{22}$ Nuestro propósito ha sido ofrecer una síntesis temática y adelantar nuevas hipótesis e interpretaciones.

En comparación con nuestro trabajo anterior, ${ }^{93}$ son escasos los nuevos ejemplos registrados: alrededor de 15 imágenes, en unos diez manuscritos, no representan un aumento importante. Este incremento concierne sobre todo al altiplano, ya que sólo se añadieron cuatro imágenes de códices mixtecos. La repartición geográfica de las representaciones tampoco ha cambiado significativamente. Resulta interesante la cantidad de ilustraciones (65) para el

91. Caso, Interpretación del Códice Selden 3135 (A.2).

92. Garza Tarazona, Ánalisis de la arquitectura; John F. Molloy, Ball Courts and the Oaxaca Codices; Nicholson y Quiñones Keber, "Ballcourt Images".

93. Taladoire, Les Terrains de jeu de balle. 
altiplano en general, y la cuenca de México en específico. La escasez de canchas arqueológicas preservadas en esta región, en comparación con Oaxaca, Veracruz o el área maya, ha dificultado su estudio arqueológico. ${ }^{94}$ En este respecto, los manuscritos pictográficos proporcionan, para la época de la Conquista, una imagen inédita de la repartición de las canchas en esta parte de Mesoamérica. Curiosamente, a pesar de los numerosos manuscritos y documentos relativos a la región de Cholula y Tlaxcala, la escasez de imágenes en esta área es un fenómeno que encuentra cierta resonancia en las fuentes escritas coloniales, en las cuales faltan las referencias al juego, salvo el mismo Muñoz Camargo. ${ }^{95}$ ¿Será que el juego no tuvo en esta región la misma importancia que en la cuenca de México?96 Al contrario, las imágenes del Dresdensis (1975) y de Santa Rita ${ }^{97}$ y una referencia ambigua de Landa ${ }^{98}$ contradicen la falta total de canchas del Posclásico tardío en Yucatán.

Un detalle cronológico merece nuestra atención por sus consecuencias en la supervivencia del juego. Se justifican perfectamente las representaciones de canchas en los códices prehispánicos, del principio de la colonia, y hasta las de los cronistas como Durán y Sahagún, anteriores a la prohibición del juego. Su supervivencia en documentos más tardíos como la obra de Muñoz Camargo, ${ }^{99}$ el Códice de Xalapa ${ }^{100}$ o el documento del $\mathrm{AGN}^{101}$ resulta más sorprendente. Por supuesto, las canchas habían perdido su función principal y su simbolismo, pero, a pesar de la supuesta desaparición del juego, éstas seguían siendo un elemento identificable de la topografía urbana, incluso para las instituciones virreinales.

94. Francisco Beristáin Bravo, "Análisis arquitectónico del juego de pelota en el área central de México", Revista Mexicana de Estudios Antropológicos, t. 29, núm. I (1996): 211-242.

95. Manuel Carrera Stampa, Algunos aspectos de la Historia de Tlaxcala de Diego Muñoz Camargo, Estudios de Historiografía de la Nueva España (México: El Colegio de México, I945), 9I-I42.

96. A pesar de los resultados obtenidos por medio de varios proyectos en esta región (Fundación Alemana, A. García Cook, e. g.) que permitieron documentar numerosas canchas, escasos son los ejemplos del Posclásico. Véase, por ejemplo, Ángel García Cook y Beatriz Leonor Merino Carrión, "Cantona: urbe prehispánica en el altiplano central de México", Latin-American Antiquity 9, núm. 3 (1988).

97. Jourdan, Santa Rita. Les peintures murales de la structure I.

98. Taladoire, Les Terrains de jeu de balle.

99. Muñoz Camargo, Historia de Tlaxcala.

ıoo. Taladoire, "Le Codex de Jalapa, ou mapa del juego de pelota", III-II8.

Ior. Martos y Pulido Méndez, "Un juego de pelota en la ciudad de México", 8I-87. 
5. Códice Nuttall, fol. 3. Topónimo en documento mixteco. Escena de decapitación de ir Serpiente (Xochiquetzal), tomado de The Codex Nuttall. A Picture Manuscript from Ancient Mexico, introd. Arthur G. Miller (Nueva York: Dover Publications, 1975), s.p.

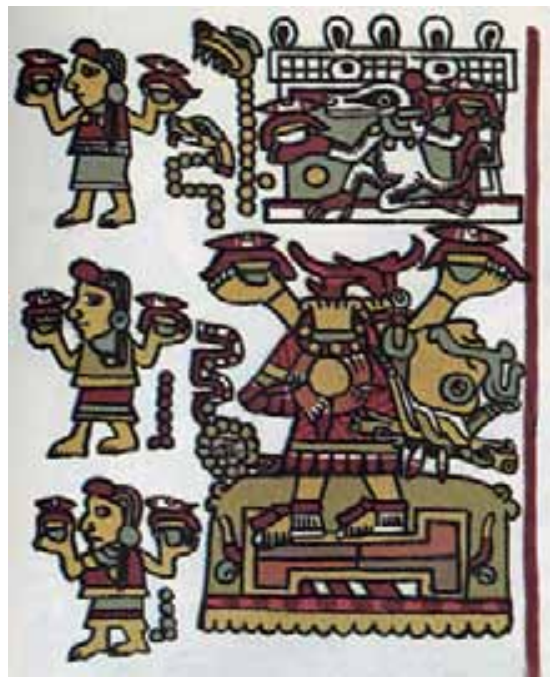

Morfológicamente, de lo expuesto pueden deducirse datos nuevos. La importancia de la forma en $\mathrm{H}$ de las canchas basta para identificarlas. A diferencia de los arqueólogos que dedican tanta (y más) atención a las estructuras asociadas (laterales, terminales, las escaleras, entre otras), los tlacuiloques sólo representaban la cancha por la morfología de la zona de juego, como si fuera suficiente. Asimismo, los arqueólogos enfocan su atención sobre los monumentos asociados, los anillos sobre todo. Hemos subrayado el escaso número de imágenes de canchas con anillos (26 de 157), ubicadas principalmente en el altiplano. ${ }^{102}$ Pero la mayoría de ellas carecen de anillos, como si no fueran elementos esenciales. Eso coincide con la escasez de anillos documentados, incluso en el Posclásico del altiplano.

Al contrario, el centro de la cancha es el enfoque de la inmensa mayoría de las representaciones; puede simbolizarse con motivos como círculos, chalchihuites, cráneos, escenas de sacrificio, de parto, pero también como el punto donde se cruzan las líneas que dividen la cancha en cuadrantes. Es del centro de donde sale el sol naciente (Vindobonensis). En sus distintas representaciones, el centro ilustra obviamente el lugar más simbólico. Los mitos mexicas también confirman su importancia: es el Itzompan del mito de la peregrinación

I02. Solís Olguín, "Estudio de los anillos de juego de pelota: el origen de este elemento", 255-26I. 
azteca. ${ }^{\mathrm{IO}} \mathrm{La}$ intervención de Huitzilopochtli en Tula permite el surgimiento del agua y de la vegetación del Itzompan en el centro de tlachco. El que el responsable de este rito agrario sea de hecho el dios guerrero Huitzilopochtli no es una coincidencia, sino una manifestación del concepto de complementariedad en la perspectiva dualista mesoamericana. ${ }^{104}$

El centro de las canchas nunca ha sido el enfoque de un estudio arqueológico específico, aun si abundan las evidencias de su importancia. ${ }^{105}$ En numerosas canchas de la zona maya, los marcadores decorados con dirigentes, jugadores e inscripciones definen el centro. Su buena conservación demuestra que no sirvieron en el juego, porque hubieran resultados dañados por los golpes. Tanto en la Mixteca como en el altiplano, casi no tenemos datos al respecto, salvo unos escasos discos de piedra lisa. ${ }^{106}$ Pero otras esculturas como los anillos, las esculturas con espigas dispuestas en las estructuras laterales definen líneas imaginarias que pasan por el centro. Varias ofrendas, depósitos intencionales y posibles vestigios de sacrificios se encontraron al centro de las canchas en toda Mesoamérica. ${ }^{107} \mathrm{Si}$, como escriben algunos cronistas, se trazaban líneas sobre el piso de las canchas para jugar, como ocurre hoy día en el ulama, ${ }^{108}$ desgraciadamente no dejaron huellas. Los documentos pictográficos abren así una pista de investigación inédita sobre este punto fundamental.

Las funciones básicas estaban ya definidas: los nuevos datos no modifican lo que se sabía. Sólo notamos una ligera diferencia entre el altiplano y la zona mixteca en el uso del tlachco como antropónimo.

El aspecto simbólico es mucho más relevante. Quisiera primero regresar a la escasa asociación entre los juegos de pelota y el signo ollin. A diferencia de todo lo que se escribió al respecto, existe uno que otro ejemplo, tanto en los manuscritos como en la iconografía. ${ }^{109}$ Pero esta asociación no tiene la importancia que se le atribuía previamente. Todos hemos sobreestimado o malin-

I03. Alvarado Tezozómoc, Crónica mexicana.

I04. Alfredo López Austin, "El núcleo duro, la cosmovisión y la tradición mesoamericana", en Cosmovisión, ritual e identidad de los pueblos indígenas de México, eds. Johanna Broda y Jorge Félix Báez (México: Consejo Nacional para la Cultura y las Artes/Fondo de Cultura Económica, 200I), 47-65.

I05. Taladoire, "El centro del Tlachco".

I06. Barrois, "Les Sculptures associées aux jeux de balle".

I07. Taladoire, "El centro del Tlachco".

108. Ted J.J. Leyenaar, Ulama. The Perpetuation in Mexico of the Pre-Spanish Ballgame Ullamaliztli (Leiden: Brill, 1978); Ulama: The Survival of the Pre-Columbian Ballgame.

ı09. Castillo Peña, La expresión simbólica del Tajín. 
terpretado el concepto de movimiento en relación con la pelota, en el marco de una interpretación astral del juego, ${ }^{\text {IIO }}$ relacionada con el ciclo solar. Al contrario, todas las evidencias coinciden en una versión del juego en términos de rito de fertilidad, de ciclo diurno o de temporadas, en una concepción de alternancia complementaria, de dualidad, más conforme con lo que conocemos ahora de la cosmogonía mesoamericana. ${ }^{I I I}$

No se puede de manera provisional sacar conclusiones significativas de la distribución de los colores en las canchas, salvo la predominancia de rojo y el contraste frecuente entre rojo y negro (luz y oscuridad), o entre rojo y verde o azul, ambos colores asociados a la fertilidad bajo perspectivas diferentes y complementarias. Este simbolismo refleja la vinculación de las canchas con el complejo de deidades asociadas. Este último pertenece casi de forma integral al complejo que Nicholson ${ }^{\text {II2 }}$ considera relacionado con la agricultura, la fertilidad o, en otro enfoque, la alternancia entre la luz y la oscuridad o sea el ciclo diurno y la alternancia de las temporadas. Asimismo, entre los motivos asociados, la abundancia de elementos acuáticos (la lluvia, el agua, el color verde, los chalchihuites, el maguey y el pulque entre otros), de referencias a la tierra y a la noche, al inframundo (el cocodrilo, el jaguar) confirma esta lectura. Al mismo tiempo, varios motivos hacen referencia a la guerra, a las armas, a la Conquista. Lejos de ser contradictorios, ambos temas son perfectamente complementarios en el dualismo mesoamericano. La guerra y la agricultura son las dos facetas complementarias de la sociedad, de la economía y del cosmos. Huitzilopochtli y Tláloc comparten el Templo Mayor, la Montaña Sagrada. ${ }^{113}$ Cuando el tlatoani mexica Axayácatl quiso apoderarse de las riquezas agrícolas de Xochimilco apostó su reino en el juego contra Xihuiltémoc. ${ }^{\mathrm{II} 4}$ Ambas facetas del juego encuentran su unidad en el sacrificio, por decapitación o cardiectomía, un tema omnipresente en los manuscritos.

IIo. Krickeberg, "El juego de pelota mesoamericano y su simbolismo religioso"; Seler, Gesammelte Abhandlungen.

III. López Austin, "El núcleo duro, la cosmovisión y la tradición mesoamericana", 47-65.

II2. Nicholson, "Religion in Pre-Hispanic central Mexico".

II3. Alfredo López Austin y Leonardo López Luján, Monte Sagrado-Templo Mayor (México: Instituto Nacional de Antropología e Historia/Universidad Nacional Autónoma de México-Instituto de Investigaciones Antropológicas, 2009).

II4. Barbara F. Fash y William L. Fash, "Religion, Politics and Plenty of Betting. The Old Ball Game in Mesoamerica", ReVista (primavera, 20I2): 30-34. 
Los mismos temas están abundantemente documentados tanto en la arqueología como en la iconografía. Los monumentos que representan escenas de decapitación son innumerables (Chichén Itzá, El Tajín, Aparicio, Yaxchilán, entre otros), algunos ilustran el juego como rito de fertilidad (Copán, El Tajín). ${ }^{115}$ Los guerreros de los marcadores de la cancha de Tenam Rosario, ${ }^{116}$ en posición de parto (como en el Códice Borgia 40) demuestran también esta ambivalencia guerra-fertilidad. En varios lugares de Chiapas, Toniná o Yaxchilán, el juego de pelota se interpreta como sustituto o consecuencia de guerras. ${ }^{117}$ Esta complementariedad refleja la alternancia de las temporadas: las lluvias permiten la cosecha, las cosechas abastecen la guerra y son el motivo de las conquistas en la temporada seca, en un ciclo continuo. Las canchas múltiples del Vindobonensis (7, 19), las canchas dobles negras y rojas del Nuttall, los tlachco bordados de estrellas del Borgia, del Laud, del Vindobonensis o del Nuttall son ilustraciones manifiestas de esta alternancia. Todas las representaciones pictográficas de canchas, aunque con sus especificidades conforme con los manuscritos, se ubican en el marco de un concepto compartido de dualidad, de alternancia de las temporadas del ciclo vital y vegetal.

Esta dualidad compartida tiene raíces muy antiguas, como lo atestiguan las evidencias arqueológicas. Además de las múltiples semejanzas iconográficas ya mencionadas, la ubicación de las canchas en el contexto urbanístico mesoamericano refleja el mismo simbolismo. ${ }^{I 8} \mathrm{El}$ tlachco, elemento constitutivo del centro ceremonial mesoamericano, contrasta y complementa dos contextos arquitectónicos asociados: la pirámide y el palacio. La pirámide evoca el nivel celeste, divino, el hogar de los antepasados, la montaña sagrada. El palacio corresponde al mundo de los humanos, de los dirigentes responsables del ciclo solar y del juego. El tlachco es la puerta del inframundo, del mun-

II5. Eric Taladoire, "To the Underworld and Back: a Lasting Symbolism of the Ballgame. Teotihuacan to Tenochtitlan. Cultural Continuity in Central Mexico", en Homage to Alfredo López Austin (Los Ángeles: Art History Society of California State University, 2012).

II6. Olivier de Montmollin, “Tenam Rosario. A Political Microcosm”, American Antiquity 53, núm. 2 (1988): 351-370; John Gerard Fox, "The Ballcourt Markers of Tenam Rosario, Chiapas, Mexico", Ancient Mesoamerica, 4 (I) (1933): 55-64.

I17. Eric Taladoire y Benoît Colsenet, "Bois ton sang, Beaumanoir. The Political and Conflictual Aspects of the Ballgame in Northern Chiapas", en International Symposium on the Mesoamerican Ballgame and Ball-courts, eds. Vernon L. Scarborough y David Wilcox (University of Arizona Press, I99I), I6I-I74.

II8. Taladoire, To the Underworld and Back. 
DOI: http://dx.doi.org/10.22201/iie.18703062e.2015.106.2544

LAS APORTACIONES DE LOS MANUSCRITOS PICTOGRÁFICOS

do nocturno, donde baja y de donde nace el sol, de donde brotan las plantas, la vida, el agua, como lo representan los manuscritos. Este patrón urbanístico se evidencia en Uxmal, Copán, Monte Albán, así como en sitios menores de Veracruz, del área de Teuchitlan y finalmente en Tenochtitlan. No debe sorprendernos entonces si los documentos pictográficos afirman este conjunto simbólico, que manifiesta la unidad intrínseca del juego como tradición milenaria. \$ 
DOI: http://dx.doi.org/10.22201/iie.18703062e.2015.106.2544

210

ERIC TALADOIRE

Anexo I. Repartición geográfica de procedencia de las representaciones

\begin{tabular}{|c|c|c|c|c|}
\hline Altiplano & Borgia & Mixteca & Costa del Golfo & Maya \\
\hline AGN & Borgia & Becker I & San Juan Nayotla & Dresdensis \\
\hline Tonalamatl Aubin & Fejérváry Mayer & Becker II & & \\
\hline Codex Aubin & Laud & Bodley & & \\
\hline Azcatitlán & Vaticano Ríos & Colombino & & \\
\hline Borbonicus & & Egerton & & \\
\hline Códice en cruz & & Lienzo Antonio de León & & \\
\hline Codex des 20 mazorcas & & Lienzo de Ihuitlán & & \\
\hline Codex mexicano & & Lienzo Tepepelme III & & \\
\hline Codex de Xalapa & & Lienzo de Tlapiltepec & & \\
\hline Durán & & Lienzo de Tlacoatzintepec & & \\
\hline Florentino & & Nuttall & & \\
\hline García Granados & & Porfirio Díaz & & \\
\hline Historia Mexicana & & Selden I & & \\
\hline Historia tolteca-chichimeca & & Selden II & & \\
\hline Lienzo Quauhquechollan & & Vindobonensis & & \\
\hline Magliabechiano & & & & \\
\hline Mapa de Coatlan & & & & \\
\hline Mapa Cozcatzin & & & & \\
\hline Mapa de Cuauhtinchan I & & & & \\
\hline Mapa de Cuauhtinchan 2 & & & & \\
\hline Mapa de Cuauhtinchan 3 & & & & \\
\hline Mapa Sto. T. Ocotepeque & & & & \\
\hline Mapa de Sigüenza & & & & \\
\hline Mapa de Metlatoyuca & & & & \\
\hline Matrícula de tributos & & & & \\
\hline Mendoza & & & & \\
\hline Migración azteca & & & & \\
\hline $\mathrm{Ms} \mathrm{n}^{\circ} 4$ de I7I 4 & & & & \\
\hline Códice Moctezuma & & & & \\
\hline Muñoz Camargo & & & & \\
\hline Osuna & & & & \\
\hline Ms Pleito de tierras & & & & \\
\hline Primeros memoriales & & & & \\
\hline Telleriano Remensis & & & & \\
\hline Título Santa Isabel Tola & & & & \\
\hline Tudela & & & & \\
\hline Xolotl & & & & \\
\hline Total & 4 & I5 & I & I \\
\hline
\end{tabular}


DOI: http://dx.doi.org/10.22201/iie.18703062e.2015.106.2544

LAS APORTACIONES DE LOS MANUSCRITOS PICTOGRÁFICOS

Anexo 2. Topónimos de juego de pelota identificados en los manuscritos pictográficos

\begin{tabular}{|c|c|c|}
\hline Topónimo & Lugar & Referencias \\
\hline Tlachco & Taxco & $\begin{array}{l}\text { Matrícula de tributos io, Matrícula de tributos II, } \\
\text { Mendoza 8, Mendoza 3I, Mendoza 36, Rollo Selden } \\
\text { 3207, Vaticano Ríos 82V }\end{array}$ \\
\hline Tlachco & Querétaro & Mapa de Coatlan, Migración azteca, Códice Moctezuma \\
\hline Tlachapa & \multirow[t]{5}{*}{ Tlachapa (Hgo.) } & \\
\hline Tlachuacalco & & \\
\hline Zacatlachco & & Lienzo San Juan Nayotla \\
\hline Tlachmalacac & & $\begin{array}{l}\text { Matrícula de tributos 16, Mendoza 37, Vindobonensis I3, } \\
\text { Vindobonensis }\end{array}$ \\
\hline Tlachquiauhco & & $\begin{array}{l}\text { Aubin 19, } 20 \text { Mazorcas, Historia Mexicana, Mendoza } \\
\text { I6, Mendoza } 45 \text { Telleriano Remensis, Vaticano Ríos I30, } \\
\text { Matrícula } 9\end{array}$ \\
\hline $\begin{array}{l}\text { Tlachyahualco } \\
\text { Tlachyahualpa }\end{array}$ & $\begin{array}{l}\text { Santa Ana } \\
\text { Tlachyahualco }\end{array}$ & Matrícula de tributos 3, 6, Mendoza 2I \\
\hline Tlalachco & Ca Teotenango & Matrícula de tributos I5, Mendoza 32, Osuna \\
\hline Tlachtitlan & & $\begin{array}{l}\text { Ms. Pleito de tierras, Título de tierra Santa Isabel Tola, } \\
\text { Ms. } n^{\circ} 4\end{array}$ \\
\hline Tlacachtitlan & \multirow{6}{*}{ Tlaxiaco } & Mapa Cozcatzin \\
\hline Tlachcu Tepitu & & Mapa de Sto. Tomas Ocotepeque \\
\hline ¿Tututepec? & & Nuttall 45 \\
\hline Tlaxiaco & & Vaticano Ríos 84 \\
\hline $\begin{array}{l}\text { Juego de la } \\
\text { noche }\end{array}$ & & Vindobonensis 3, Vindobonensis 44 \\
\hline $\begin{array}{l}\text { Río del juego } \\
\text { de pelota }\end{array}$ & & Colombino 2 VI, 6 XIV \\
\hline
\end{tabular}


DOI: http://dx.doi.org/10.22201/iie.18703062e.2015.106.2544

$2 \mathrm{I} 2$

ERIC TALADOIRE

Anexo 3. Catálogo de motivos recurrentes asociados con las canchas

\begin{tabular}{|c|c|c|c|}
\hline Simbolos/motivos & Procedencia & núm. & total \\
\hline pelota & $\begin{array}{l}\text { Aubin I9, Florentino, Laud 40, Muñoz Camargo, } \\
\text { Vindobonensis I3, 20, } 22\end{array}$ & 8 & 9 \\
\hline ollin & Borbónico 27 & I & \\
\hline decapitación & Aubin 19, Borbónico 19, Nuttall 3, Vindobonensis 20, 22 & 5 & 26 \\
\hline tzompantli & Primeros memoriales & I & \\
\hline cráneo & $\begin{array}{l}\text { Borbónico 19, 27, Borgia 21, Magliabechiano, Nuttall 4, } \\
\text { Tudela }\end{array}$ & 6 & \\
\hline corazones & Borbónico 27, Borgia 21 & 2 & \\
\hline hueso, esqueleto & Borgia $2 \mathrm{I}, 4 \mathrm{O}$ & 2 & \\
\hline sacrificio & Azcatitlán, Borgia 2I, 35, Nuttall 2I, 44, 45, Rollo Selden & 7 & \\
\hline cuchillo & Nuttall 8, 67, Tudela & 3 & \\
\hline armas & Aubin 79 & I & I8 \\
\hline guerreros & $\begin{array}{l}\text { Colombino XXI, Nuttall 2I, 80, Selden II } 8 \text { IV, II } 9 \text { II, } \\
\text { Vaticano Ríos 82v }\end{array}$ & 6 & \\
\hline conquista & Mendoza 8, 36, Nuttall 74, Telleriano Remensis 42v & 4 & \\
\hline llamas & Nuttall 2, Selden II I I, Vindobonensis 3, 7, I7, I9 & 6 & \\
\hline fuego & Nuttall 4 , & I & \\
\hline lluvia & $\begin{array}{l}\text { Aubin 79, } 20 \text { mazorcas, C. Mexicano, Historia Mexicana, } \\
\text { Matrícula de tributos I6, Mendoza I6, 45, Telleriano } \\
\text { Remensis 4Ir, 42v, Vaticano Ríos 84, 82v }\end{array}$ & II & 32 \\
\hline agua & $\begin{array}{l}\text { Borbónico 19, Colombino, II 6, VI I4, Dresdensis, Nuttall } \\
44\end{array}$ & 5 & \\
\hline piedras verdes & Durán & I & \\
\hline plumas verdes & Durán, Laud 40, & 2 & \\
\hline chalchihuitl & Borgia 40, Nuttall 74 & 2 & \\
\hline plantas & Durán & I & \\
\hline maguey & Vindobonensis I3, 20, 22 & 3 & \\
\hline tierra & Mendoza 32, Matrícula de tributos I5 & 2 & \\
\hline malacate & $\begin{array}{l}\text { Matrícula de tributos } 15 \text {, Mendoza } 37 \text {, Vindobonensis I3, } \\
\text { 22, Vindobonensis }\end{array}$ & 5 & \\
\hline
\end{tabular}


DOI: http://dx.doi.org/10.22201/iie.18703062e.2015.106.2544

LAS APORTACIONES DE LOS MANUSCRITOS PICTOGRÁFICOS

\begin{tabular}{|c|c|c|c|}
\hline Simbolos/motivos & Procedencia & núm. & total \\
\hline águila/quetzal & $\begin{array}{l}\text { Becker II 2, Colombino VI I4, Nuttall I2, 45, 83, } \\
\text { Vindobonensis I7 }\end{array}$ & 6 & $2 \mathrm{I}$ \\
\hline perro/coyote & $\begin{array}{l}\text { Bodley } 36 \text { II, Mapa Cozcatzin, Título de tierra Santa Isabel } \\
\text { Tola }\end{array}$ & 3 & \\
\hline venado & Laud 40 & I & \\
\hline $\begin{array}{l}\text { serpiente/ } \\
\text { cocodrilo }\end{array}$ & Borbónico 27, Borgia 21, 35, Nuttall I5, I7, I8, 19, 25 & 8 & \\
\hline lagarto & Fejérváry Mayer & I & \\
\hline jaguar & Vindobonensis 29, Nuttall 45 & 2 & \\
\hline estrellas & $\begin{array}{l}\text { Borgia 35, 40, Laud 40, Nuttall I2, I5, I7, I8, I9, 22, } \\
\text { Vindobonensis 43, } 44\end{array}$ & II & 15 \\
\hline observatorio & Selden II 5 III, 5 IV & 2 & \\
\hline pies & Nuttall 2, 4, & 2 & \\
\hline cerro & $\begin{array}{l}\text { Bodley } 2 \text { IV, I2 III, Lienzo de Tlapiltepec, Mapa de } \\
\text { Cuauhtinchan 2, Nuttall I, 3, 8, I2, 45, Vindobonensis 3, } \\
43,44\end{array}$ & 12 & $\mathrm{I} 2$ \\
\hline corona real & Osuna & I & 4 \\
\hline cruces & Lienzo de Tlacoatzintepec & I & \\
\hline camino & Mapa de Cuauhtinchan 2, Vindobonensis I3 & 2 & \\
\hline
\end{tabular}


DOI: http://dx.doi.org/10.22201/iie.18703062e.2015.106.2544

$2 \mathrm{I} 4$

ERIC TALADOIRE

Anexo 4. Síntesis de las temáticas recurrentes en relación con la dualidad prehispánica

\begin{tabular}{llllll}
\hline Aspecto & Colores & Deidades & Motivos & Animales & Escenas \\
\hline femenino & rojo & Chac & lluvia & serpiente & parto \\
húmedo & negro & Tezcatlipoca & agua & coyote & decapitación \\
nocturno & azul & Ixtlilton & ríos & cocodrilo & \\
terrestre & verde & Centéotl & cráneos & jaguar & \\
fertilidad & negro & Cihuacóatl & tzompantli & lagarto & \\
& & Ehécatl & maguey & venado & \\
& & Quetzalcóatl & chalchihuitl & & \\
& & Yohualtecuhtli & malacates & & \\
& & Tlazoltéotl & estrellas & & \\
masculino & verde & Techiquetzal & tierra & & conflicto \\
seco & azul & & zacate & águila & guerra \\
diurno & & & ollin & quetzal & conquista \\
celeste & & tzompantli & & cardiectomía? \\
guerra & & corazones & & \\
& & guerreros & & \\
\hline
\end{tabular}


LAS APORTACIONES DE LOS MANUSCRITOS PICTOGRÁFICOS

\section{Anexo 5. Registro de las representaciones y de los principales símbolos asociados}

\begin{tabular}{|c|c|c|c|c|c|}
\hline Manuscritos & & Función & Morfología & Simbolos y motivos asociados & Deidades e individuos \\
\hline AGN & I & cancha & $\mathrm{H}$, línea sencilla & & \\
\hline Tonalamatl Aubin I9 & I & simbólica & $\begin{array}{l}\mathrm{H} \text {, doble línea, círculo } \\
\text { central }\end{array}$ & ¿pelota? decapitación & Xochiquetzal, $19^{\mathrm{e}}$ trecena \\
\hline Codex Aubin 79 & I & $\begin{array}{l}\text { topónimo } \\
\text { (Tlachquiyauhco) }\end{array}$ & $\mathrm{H}$, línea sencilla & lluvia, atlatl y escudo & \\
\hline Azcatitlán $89 / 342$ & I & simbólica & $\mathrm{U}$ (mitad), doble línea & sacrificio humano & \\
\hline Becker I 8 & I & ¿antropónimo? & $\mathrm{H}$, doble línea & ¿? & \\
\hline Becker II 2 & I & antropónimo & $\mathrm{H}$, doble línea & águila & \\
\hline Bodley 2858,2 IV & 4 & antropónimo & $\mathrm{H}$ (mitad), doble línea & cerro, $1 / 2$, individuo & 3 Lluvia-Tlachco \\
\hline Bodley 2858 , Io II & & simbólica & $\begin{array}{l}\mathrm{H} \text {, línea triple, círculo } \\
\text { central, grecas laterales }\end{array}$ & jugadores & 3 Ollin y 8 Venado (cráneo) \\
\hline Bodley 2858, I2 III & & topónimo & $\begin{array}{l}\mathrm{H} \text {, doble línea, grecas } \\
\text { laterales }\end{array}$ & cerro, dos individuos & ¿I Serpiente? \\
\hline Bodley 2858,36 II & & topónimo & $\begin{array}{l}\text { ¿H, doble línea, centro? } \\
\text { grecas laterales }\end{array}$ & ¡coyote? & \\
\hline Borbonicus I9 & 2 & simbólica & $\begin{array}{l}\text { H, doble línea, anillos, } \\
\text { centro (cráneo) }\end{array}$ & $\begin{array}{l}\text { cráneo sangrante, decapitación, } \\
\text { agua en anillo }\end{array}$ & Xochiquetzal, $19^{\mathrm{e}}$ trecena \\
\hline Borbonicus 27 & & simbólica & $\begin{array}{l}\mathrm{H}, \text { línea triple, anillos, } \\
\text { centro (serpientes/ollin) }\end{array}$ & $\begin{array}{l}\text { cráneos, serpientes, ollin, } \\
\text { corazones }\end{array}$ & $\begin{array}{l}\text { Ixtlilton, Centéotl, } \\
\text { Cihuacóatl, Ehecatl }\end{array}$ \\
\hline Borgia 2I & 4 & simbólica & $\mathrm{H}$, línea triple, anillos, & $\begin{array}{l}\text { cráneos, corazones, hueso, } \\
\text { serpientes, sacrificio }\end{array}$ & $\begin{array}{l}\text { Tezcatlipoca rojo, } \\
\text { Tezcatlipoca negro }\end{array}$ \\
\hline Borgia 35 & & simbólica & $\mathrm{H}$, línea triple, centro & cocodrilo, sacrificio, estrellas & $\begin{array}{l}\text { Quetzalcóatl, Yohualtecuhtli, } \\
\text { Tonacatecuhtli }\end{array}$ \\
\hline Borgia 40 & & simbólica & $\mathrm{H}$, línea triple, anillos, & $\begin{array}{l}\text { esqueleto, estrellas, parto, } \\
\text { chalchihuitl: salida del sol }\end{array}$ & Tezcatlipoca, Tlazoltéotl \\
\hline Borgia 42 & & simbólica & $\mathrm{H}$, línea triple, anillos, & $\begin{array}{l}\text { estrellas, sacrificio, palillos, } \\
\text { sacrificio }\end{array}$ & Quetzalcóatl \\
\hline Códice en cruz & I & cancha & $\mathrm{H}$, doble línea (parcial) & & \\
\hline Codex des 20 mazorcas & I & $\begin{array}{l}\text { topónimo } \\
\text { (Tlachquiyauhco) }\end{array}$ & $\begin{array}{l}\mathrm{H} \text {, doble línea } \\
\text { (discontinua), centro }\end{array}$ & lluvia & \\
\hline Codex Mexicano & I & topónimo & $\mathrm{H}$, doble línea & lluvia & \\
\hline Codex de Xalapa (35-73) & I & cancha & $\mathrm{H}$, línea sencilla & & \\
\hline Colombino II-6 & 4 & ¡topónimo? & H, doble línea, centro & flujo de agua & ¿I Jaguar? 8 Venado \\
\hline Colombino VI-I4 & & topónimo & $\mathrm{H}$, doble línea, centro? & ¿flujo de agua, ave? & I Acatl \\
\hline Colombino XI & & simbólica & $\mathrm{H}$, doble línea & 6 jugadores & Dioses (día y noche) \\
\hline Colombino XXI & & $\begin{array}{l}\text { ¿topónimo? } \\
\text { (borrado) }\end{array}$ & $\mathrm{H}$, doble linea, grecas & dos guerreros & ¿6 Jaguar 8 Venado? \\
\hline
\end{tabular}


DOI: http://dx.doi.org/10.22201/iie.18703062e.2015.106.2544

216

ERIC TALADOIRE

\begin{tabular}{|c|c|c|c|c|c|}
\hline Manuscritos & & Función & Morfología & Simbolos y motivos asociados & Deidades e individuos \\
\hline Dresden 4Ia & I & simbólica & $\begin{array}{l}\text { Perfil, línea doble, centro } \\
\text { (espiral) }\end{array}$ & espiral (agua), individuo & \\
\hline Durán, cap. 23 lám. II & I & cancha & $\begin{array}{l}\text { H, doble línea } \\
\text { (rectángulo), anillos }\end{array}$ & $\begin{array}{l}\text { plantas, jugadores, piedras } \\
\text { verdes, plumas verdes }\end{array}$ & \\
\hline Egerton 289513 & I & antropónimo & $\mathrm{H}$, doble línea & & ¿dirigente? \\
\hline Fejérváry Mayer 38 & I & simbólica & $\mathrm{H}$, doble línea, centro, & fecha, lagarto & \\
\hline $\begin{array}{l}\text { Florentino VIII: 9I, } \\
\text { 42r: II }\end{array}$ & I & cancha & $\begin{array}{l}\mathrm{H} \text {, doble línea, estr. } \\
\text { laterales, anillos }\end{array}$ & pelota, jugadores & \\
\hline García Granados 35-49 & 2 & topónimo & $\mathrm{H}$, línea sencilla & & \\
\hline García Granados 35-49 & & ‘topónimo? & $\mathrm{H}$, línea sencilla & & \\
\hline Historia mexicana & I & $\begin{array}{l}\text { topónimo } \\
\text { (Tlachquiyauhco) }\end{array}$ & $\mathrm{H}$, doble línea & lluvia & \\
\hline $\begin{array}{l}\text { Historia tolteca- } \\
\text { chichimeca I6 }\end{array}$ & 2 & cancha & $\mathrm{H}$, doble línea, centro & & $\begin{array}{l}\text { Cuauhtlixtac, Apanécatl } \\
\text { (dirigentes) }\end{array}$ \\
\hline $\begin{array}{l}\text { Historia tolteca- } \\
\text { chichimeca 3I }\end{array}$ & & cancha & $\mathrm{H}$ & jugadores & \\
\hline Laud 40 & 2 & ¿cancha? & $\mathrm{H}$, doble línea & pelota, fecha, venado & \\
\hline Laud 40 & & topónimo & $\mathrm{H}$, doble línea & estrellas, paquetes de plumas & \\
\hline Lienzo Antonio de León & 2 & ¡antropónimo? & $\mathrm{H}$, doble línea, centro & & I3 Lagarto \\
\hline Lienzo Antonio de León & & topónimo & $\mathrm{H}$, doble línea, centro & & \\
\hline $\begin{array}{l}\text { Lienzo San Juan Nayotla } \\
35-97\end{array}$ & I & $\begin{array}{l}\text { topónimo } \\
\text { (Zacatlachco) }\end{array}$ & $\mathrm{H}$, cuatro rectángulos & & \\
\hline Lienzo de Ihuitlan & I & topónimo & $\begin{array}{l}\mathrm{H} \text {, línea sencilla, en un } \\
\text { rectángulo }\end{array}$ & & \\
\hline $\begin{array}{l}\text { Lienzo de } \\
\text { Quauhquechollan }\end{array}$ & I & topónimo & $\mathrm{H}$, línea sencilla & & \\
\hline $\begin{array}{l}\text { Lienzo de Tlapiltepec } \\
\text { Lienzo de Tlapiltepec }\end{array}$ & 2 & $\begin{array}{l}\text { topónimo } \\
\text { topónimo }\end{array}$ & $\begin{array}{l}\mathrm{H} \text {, doble línea, centro } \\
\mathrm{H} \text {, doble línea, centro }\end{array}$ & chapullin, tepetl & \\
\hline $\begin{array}{l}\text { Lienzo de } \\
\text { Tlacoatzintepec }\end{array}$ & I & topónimo & $\mathrm{H}$, doble línea & cruces & \\
\hline $\begin{array}{l}\text { Lienzo Tepepelme III } \\
\text { Lienzo Tepepelme III }\end{array}$ & 2 & $\begin{array}{l}\text { topónimo } \\
\text { topónimo }\end{array}$ & & & \\
\hline Magliabechiano 80 & I & cancha & $\begin{array}{l}\text { H, doble línea, anillos, } \\
\text { centro }\end{array}$ & 7 cráneos, jugadores & Mictlantecuhtli \\
\hline Mapa de Coatlan & I & $\begin{array}{l}\text { topónimo } \\
\text { (Tlachco) }\end{array}$ & $\mathrm{H}$, línea sencilla & & \\
\hline
\end{tabular}


DOI: http://dx.doi.org/10.22201/iie.18703062e.2015.106.2544

LAS APORTACIONES DE LOS MANUSCRITOS PICTOGRÁFICOS

\begin{tabular}{|c|c|c|c|c|c|}
\hline Manuscritos & & Función & Morfología & Simbolos y motivos asociados & Deidades e individuos \\
\hline Mapa Cozcatzin I3 (I) & 2 & $\begin{array}{l}\text { topónimo } \\
\text { (Tlacachtitlan) }\end{array}$ & $\begin{array}{l}\mathrm{H} \text {, doble línea (parcial), } \\
\text { centro }\end{array}$ & & \\
\hline Mapa Cozcatzin I3 (2) & & $\begin{array}{l}\text { antropónimo } \\
\text { (Tlachcuyotl) }\end{array}$ & $H$, línea sencilla & ¿perro? & \\
\hline $\begin{array}{l}\text { Mapa de Cuauhtinchan } \\
\text { I }\end{array}$ & I & ¿topónimo? & $\begin{array}{l}\mathrm{H} \text {, línea sencilla } \\
\text { (rectángulo) }\end{array}$ & & \\
\hline $\begin{array}{l}\text { Mapa de Cuauhtinchan } \\
2(5)\end{array}$ & 5 & topónimo & $\begin{array}{l}\mathrm{H} \text {, línea sencilla, estr. } \\
\text { laterales, anillos }\end{array}$ & cerro & \\
\hline $\begin{array}{l}\text { Mapa de Cuauhtinchan } \\
2(29)\end{array}$ & & topónimo & $\begin{array}{l}\mathrm{H} \text {, línea doble, estr. } \\
\text { laterales }\end{array}$ & cerro, puntos negros & \\
\hline $\begin{array}{l}\text { Mapa de Cuauhtinchan } \\
2(52)\end{array}$ & & topónimo & $\begin{array}{l}\mathrm{H} \text {, línea doble, estr. } \\
\text { laterales }\end{array}$ & dos canchas perpendiculares & \\
\hline $\begin{array}{l}\text { Mapa de Cuauhtinchan } \\
2(52)\end{array}$ & & topónimo & $\begin{array}{l}\mathrm{H} \text {, línea doble, estr. } \\
\text { laterales }\end{array}$ & dos canchas perpendiculares & \\
\hline $\begin{array}{l}\text { Mapa de Cuauhtinchan } \\
2(60)\end{array}$ & & topónimo & $\mathrm{H}$, línea doble, abierta & camino & \\
\hline $\begin{array}{l}\text { Mapa de Cuauhtinchan } \\
3 \text { (I4) }\end{array}$ & I & topónimo & $\begin{array}{l}\text { H, doble línea, } \\
\text { mampostería }\end{array}$ & & \\
\hline $\begin{array}{l}\text { Mapa de Santo Tomás } \\
\text { Ocotepeque }\end{array}$ & 5 & $\begin{array}{l}\text { topónimo } \\
\text { (Tlachcu Tepitu) }\end{array}$ & $\mathrm{H}$, línea sencilla & & \\
\hline Mapa de Sigüenza & I & topónimo & $\mathrm{H}$, línea sencilla & fecha & \\
\hline Mapa de Metlatoyuca & I & ¡topónimo? & $\mathrm{H}$, doble línea, centro & & \\
\hline Matrícula de tributos $3 \mathrm{r}$ & 6 & $\begin{array}{l}\text { topónimo } \\
\text { (Tlachyahualco) }\end{array}$ & $\begin{array}{l}\mathrm{H} \text {, doble línea, círculo } \\
\text { externo }\end{array}$ & & \\
\hline Matrícula de tributos 6r & & $\begin{array}{l}\text { topónimo } \\
\text { (Tlachyahualco) }\end{array}$ & $\begin{array}{l}\mathrm{H} \text {, doble línea, círculo } \\
\text { externo, anillos }\end{array}$ & & \\
\hline Matrícula de tributos io & & $\begin{array}{l}\text { topónimo } \\
\text { (Tlachco) }\end{array}$ & $\mathrm{H}$, doble línea, anillos & & \\
\hline Matrícula de tributos II & & $\begin{array}{l}\text { topónimo } \\
\text { (Tlachco) }\end{array}$ & $\mathrm{H}$, doble línea & ¿? & \\
\hline Matrícula de tributos Is & & $\begin{array}{l}\text { topónimo } \\
\text { (Tlallachco) }\end{array}$ & H doble línea, anillos & malacate, tierra & \\
\hline Matrícula de tributos I6 & & $\begin{array}{l}\text { topónimo } \\
\text { (Tlachmalacac) }\end{array}$ & $\mathrm{H}$, doble línea & lluvia & \\
\hline
\end{tabular}


DOI: http://dx.doi.org/10.22201/iie.18703062e.2015.106.2544

218

ERIC TALADOIRE

\begin{tabular}{|c|c|c|c|c|c|}
\hline Manuscritos & & Función & Morfología & Simbolos y motivos asociados & Deidades e individuos \\
\hline Mendoza 8 & 8 & $\begin{array}{l}\text { topónimo } \\
\text { (Tlachco) }\end{array}$ & $\mathrm{H}$, doble línea, anillos & templo en llamas & \\
\hline Mendoza I6 & & $\begin{array}{l}\text { topónimo } \\
\text { (Tlachquiyauhco) }\end{array}$ & $\mathrm{H}$, doble línea, anillos & lluvia & \\
\hline Mendoza 2I & & $\begin{array}{l}\text { topónimo } \\
\text { (Tlachyahualco) }\end{array}$ & $\begin{array}{l}\text { H doble línea, anillos, } \\
\text { círculo externo }\end{array}$ & & \\
\hline Mendoza 3I & & $\begin{array}{l}\text { topónimo } \\
\text { (Tlachco) }\end{array}$ & H doble línea, anillos & & \\
\hline Mendoza 32 & & $\begin{array}{l}\text { topónimo } \\
\text { (Tlallachco) }\end{array}$ & $\mathrm{H}$, doble línea & tierra & \\
\hline Mendoza 36 & & $\begin{array}{l}\text { topónimo } \\
\text { (Tlachco) }\end{array}$ & $\mathrm{H}$, doble línea, anillos & & \\
\hline Mendoza 37 & & $\begin{array}{l}\text { topónimo } \\
\text { (Tlachmalacac) }\end{array}$ & $\mathrm{H}$, doble línea & malacate & \\
\hline Mendoza 45 & & $\begin{array}{l}\text { topónimo } \\
\text { (Tlachquiyauhco) }\end{array}$ & $\mathrm{H}$, doble línea, anillos & lluvia & \\
\hline Migración azteca & I & $\begin{array}{l}\text { topónimo } \\
\text { (Tlachco) }\end{array}$ & $\mathrm{H}$, línea sencilla & & \\
\hline Ms. $n^{\circ} 4$ de 1714 & I & topónimo & $\begin{array}{l}\mathrm{H} \text {, doble línea parcial, } \\
\text { anillos }\end{array}$ & & \\
\hline Códice Moctezuma & I & $\begin{array}{l}\text { topónimo } \\
\text { (Tlachco) }\end{array}$ & $\begin{array}{l}\mathrm{H} \text {, doble línea, anillos, } \\
\text { grecas }\end{array}$ & & \\
\hline Muñoz Camargo I984 & I & cancha & $\mathrm{H}$, doble línea & ¿espectadores, pelota? & \\
\hline Nuttall I & $2 \mathrm{I}$ & topónimo & $\begin{array}{l}\mathrm{H} \text {, doble línea, estr. } \\
\text { laterales }\end{array}$ & cerro & 8 Viento \\
\hline Nuttall I & & topónimo & $\begin{array}{l}\mathrm{H} \text {, doble línea, estr. } \\
\text { laterales }\end{array}$ & cerro & 8 Viento \\
\hline Nuttall $_{2}$ & & topónimo & $\begin{array}{l}\mathrm{H} \text {, doble línea, estr. } \\
\text { laterales }\end{array}$ & pies, llamas & \\
\hline $\mathrm{Nuttall}_{3}$ & & topónimo & $\begin{array}{l}\mathrm{H} \text {, doble línea, estr. } \\
\text { laterales }\end{array}$ & loma, decapitación & $\begin{array}{l}\text { II Serpiente (Xochiquetzal). } \\
\text { Tlacuache }\end{array}$ \\
\hline Nuttall $_{4}$ & & topónimo & $\begin{array}{l}\text { H, doble línea, estr. } \\
\text { Laterales, centro }\end{array}$ & pies, fuego, cráneo & 7 Flor y 4 Movimiento \\
\hline Nuttall 8 & & topónimo & $\begin{array}{l}\mathrm{H} \text {, doble línea, estr. } \\
\text { laterales }\end{array}$ & cerro 2 Pedernal & \\
\hline Nuttall I2 & & topónimo & $\begin{array}{l}\mathrm{H} \text {, doble línea, estr. } \\
\text { laterales }\end{array}$ & $\begin{array}{l}\text { cerro, águila, signo del año, } \\
\text { estrellas }\end{array}$ & 4 Águila Tlachco \\
\hline
\end{tabular}


DOI: http://dx.doi.org/10.22201/iie.18703062e.2015.106.2544

LAS APORTACIONES DE LOS MANUSCRITOS PICTOGRÁFICOS

\begin{tabular}{|c|c|c|c|c|c|}
\hline Manuscritos & & Función & Morfología & Símbolos y motivos asociados & Deidades e individuos \\
\hline Nuttall is & & simbólica & $\mathrm{H}$, doble línea, & ¿serpiente, estrellas, anillo? & \\
\hline Nuttall I7 & & simbólica & $\mathrm{H}$, doble línea, & ¿serpiente, estrellas, anillo? & \\
\hline Nuttall I8 & & simbólica & $\mathrm{H}$, doble línea, & ¿serpiente, estrellas, anillo? & \\
\hline Nuttall I9 & & simbólica & H, doble línea, & ¿serpiente, estrellas, anillo? & \\
\hline Nuttall 2I & & $\begin{array}{l}\text { simbólica, } \\
\text { topónimo }\end{array}$ & $\begin{array}{l}\mathrm{H} \text {, doble línea, grecas } \\
\text { laterales }\end{array}$ & guerreros, sacrificio & Quetzalcóatl, 9 Viento \\
\hline Nuttall 22 & & topónimo & $\begin{array}{l}\mathrm{H} \text {, doble línea, estr. } \\
\text { laterales }\end{array}$ & fecha, estrellas & \\
\hline Nuttall 25 & & topónimo & $\mathrm{H}$, doble línea, & serpiente, fecha & \\
\hline Nuttall $_{44}$ & & topónimo & $\mathrm{H}$, doble línea, & $\begin{array}{l}\text { sacrificio de jaguar, flujo } \\
\text { de agua }\end{array}$ & 8 Venado, I2 Movimiento \\
\hline Nuttall $_{45}$ & & topónimo & $\begin{array}{l}\mathrm{H} \text {, doble línea, centro, } \\
\text { grecas laterales }\end{array}$ & fecha, hueso, jugador & 8 Venado, 7 Serpiente \\
\hline Nuttall $_{45}$ & & $\begin{array}{l}\text { topónimo } \\
\text { (¿Tututepec?) }\end{array}$ & $\mathrm{H}$, doble línea, & cerro, águila & \\
\hline Nuttall 67 & & antropónimo & $\mathrm{H}$, doble línea & cuchillo & 2 Venado \\
\hline Nuttall 74 & & topónimo & $\begin{array}{l}\mathrm{H} \text {, doble línea, centro, } \\
\text { grecas laterales, anillos }\end{array}$ & conquista, chalcuihuites & \\
\hline Nuttall 80 & & cancha & $\begin{array}{l}\mathrm{H} \text {, doble línea, grecas } \\
\text { laterales }\end{array}$ & guerreros, fecha & :8 Venado, 6 Jaguar? \\
\hline Nuttall 83 & & topónimo & $\begin{array}{l}\mathrm{H} \text {, doble línea, grecas } \\
\text { laterales }\end{array}$ & águila, fecha & \\
\hline Osuna & I & $\begin{array}{l}\text { topónimo } \\
\text { (Tlalachco) }\end{array}$ & $\mathrm{H}$, doble línea & corona real & \\
\hline Ms. Pleito de tierras & 2 & $\begin{array}{l}\text { topónimo } \\
\text { (Tlachtitlan) }\end{array}$ & $\begin{array}{l}\mathrm{H} \text {, línea sencilla, centro, } \\
\text { estr. laterales }\end{array}$ & & \\
\hline Ms. Pleito de tierras & & $\begin{array}{l}\text { topónimo } \\
\text { (Tlachtitlan) }\end{array}$ & $\mathrm{H}$, línea sencilla & & \\
\hline Porfirio Díaz B & 2 & antropónimo & $\mathrm{H}$, doble línea parcial & & \\
\hline Porfirio Díaz P & & ¡antropónimo? & $\mathrm{H}$, doble línea & fecha & \\
\hline $\begin{array}{l}\text { Primeros memoriales } \\
269 \mathrm{r}\end{array}$ & I & cancha & H, doble línea, anillos & $\begin{array}{l}\text { recinto sagrado, tzompantli } \\
\text { (¿Tepepulco?) }\end{array}$ & \\
\hline
\end{tabular}


DOI: http://dx.doi.org/10.22201/iie.18703062e.2015.106.2544

220

ERIC TALADOIRE

\begin{tabular}{|c|c|c|c|c|c|}
\hline Manuscritos & & Función & Morfología & Simbolos y motivos asociados & Deidades e individuos \\
\hline Selden II I I & II & antropónimo & $\mathrm{H}$, doble línea & tocado, llamas & II Agua Humeante Tlachco \\
\hline Selden II I II & & antropónimo & $\begin{array}{l}\mathrm{H} \text {, doble línea, estr. } \\
\text { laterales }\end{array}$ & & 4 Águila Tlachco \\
\hline Selden II 2 II & & antropónimo & $\begin{array}{l}\mathrm{H} \text {, doble línea, estr. } \\
\text { laterales }\end{array}$ & & 4 Águila Tlachco \\
\hline Selden II 5 I & & antropónimo & $\begin{array}{l}\mathrm{H} \text {, doble línea, estr. } \\
\text { laterales }\end{array}$ & ¿peine? & s Flor Tlachco \\
\hline Selden II 5 II & & antropónimo & $\begin{array}{l}\mathrm{H} \text {, doble línea, estr. } \\
\text { laterales }\end{array}$ & & 3 Lluvia \\
\hline Selden II s II & & antropónimo & $\begin{array}{l}\mathrm{H} \text {, doble línea, estr. } \\
\text { laterales }\end{array}$ & & \\
\hline Selden II 5 III & & antropónimo & $\begin{array}{l}\mathrm{H} \text {, doble línea, estr. } \\
\text { laterales }\end{array}$ & observatorio & I Lagarto \\
\hline Selden II 5 IV & & antropónimo & $\begin{array}{l}\mathrm{H} \text {, doble línea, estr. } \\
\text { laterales }\end{array}$ & observatorio & I Acatl \\
\hline Selden II 8 IV & & antropónimo & $\mathrm{H}$, doble línea & caballero águila & I Cocodrilo Águila \\
\hline Selden II 9 II & & antropónimo & $\mathrm{H}$, doble línea & caballero águila & I Cocodrilo Águila \\
\hline Selden II II II & & antropónimo & $\begin{array}{l}\mathrm{H} \text {, doble línea, estr. } \\
\text { laterales }\end{array}$ & & I3 Viento Tlachco de guerra \\
\hline Selden 3207 Rollo & 2 & $\begin{array}{l}\text { topónimo } \\
\text { (Tlachco) }\end{array}$ & $\mathrm{H}$, línea sencilla & & ${ }_{4}$ Viento, 4 Movimiento \\
\hline Selden 3207 Rollo & & $\begin{array}{l}\text { topónimo } \\
\text { (Tlachco) }\end{array}$ & $\mathrm{H}$, línea sencilla, centro? & sacrificio & \\
\hline Telleriano Remensis 4Ir & 2 & $\begin{array}{l}\text { topónimo } \\
\text { (Tlachquiyauhco) }\end{array}$ & $\mathrm{H}$, doble línea, anillos & lluvia & 1503 \\
\hline Telleriano Remensis 42V & & $\begin{array}{l}\text { topónimo } \\
\text { (Tlachquiyauhco) }\end{array}$ & $\mathrm{H}$, doble línea & prisionero (conquista), lluvia & I III \\
\hline $\begin{array}{l}\text { Título de tierra Santa } \\
\text { Isabel Tola }\end{array}$ & 2 & $\begin{array}{l}\text { antropónimo } \\
\text { (Tetlachcuiotl) }\end{array}$ & $\mathrm{H}$, doble línea parcial & ¿perro? & \\
\hline $\begin{array}{l}\text { Título de tierra Santa } \\
\text { Isabel Tola }\end{array}$ & & $\begin{array}{l}\text { topónimo } \\
\text { (Tlachtitlan) }\end{array}$ & $\begin{array}{l}\mathrm{H} \text {, doble línea parcial, } \\
\text { centro }\end{array}$ & & \\
\hline Tudela 67r & I & simbólica & $\mathrm{H}$, doble línea, anillos & $\begin{array}{l}7 \text { cráneos, jugadores, cuchillos } \\
\text { en los anillos }\end{array}$ & \\
\hline Vaticano Ríos 84 & 4 & $\begin{array}{l}\text { topónimo } \\
\text { (Tlaxiaco) }\end{array}$ & $\mathrm{H}$, doble línea & lluvia & \\
\hline Vaticano Ríos 82V & & $\begin{array}{l}\text { topónimo } \\
\text { (¿Tlachco?) }\end{array}$ & $\mathrm{H}$, doble línea, anillos & lluvia, guerrero & \\
\hline Vaticano Ríos I30 & & $\begin{array}{l}\text { topónimo } \\
\text { (Tlachquiyauhco) }\end{array}$ & $\mathrm{H}$, doble línea & fecha & \\
\hline Vaticano Ríos 85v & & topónimo & $\mathrm{H}$, doble línea & & \\
\hline
\end{tabular}


DOI: http://dx.doi.org/10.22201/iie.18703062e.2015.106.2544

LAS APORTACIONES DE LOS MANUSCRITOS PICTOGRÁFICOS

\begin{tabular}{|c|c|c|c|c|c|}
\hline Manuscritos & & Función & Morfología & Simbolos y motivos asociados & Deidades e individuos \\
\hline Vindobonensis 3 (2 ex) & 22 & $\begin{array}{l}\text { topónimo (Juego } \\
\text { de la noche) }\end{array}$ & $\begin{array}{l}\mathrm{H} \text {, doble línea, estr. } \\
\text { laterales }\end{array}$ & $\begin{array}{l}\text { oscuridad, llamas, dos } \\
\text { individuos, cerro }\end{array}$ & Io Lagarto y iI Serpiente \\
\hline Vindobonensis 7 ( 3 ex) & & simbólica & $\begin{array}{l}\mathrm{H} \text {, doble línea, estr. } \\
\text { laterales }\end{array}$ & $\begin{array}{l}\text { llamas, cerro apertura, salida } \\
\text { del sol }\end{array}$ & \\
\hline Vindobonensis I3 & & $\begin{array}{l}\text { topónimo } \\
\text { (Tlachmalacac) }\end{array}$ & $\mathrm{H}$, doble línea & $\begin{array}{l}\text { malacate, pelota, camino, } \\
\text { maguey }\end{array}$ & $\begin{array}{l}\text { II Serpiente Decapitada, } 4 \\
\text { Cocodrilo, II Cocodrilo }\end{array}$ \\
\hline Vindobonensis I7 (4 ex) & & topónimo & $\begin{array}{l}\mathrm{H} \text {, doble línea, estr. } \\
\text { laterales }\end{array}$ & águila o quetzal, llamas & \\
\hline Vindobonensis ig (5 ex) & & topónimo & $\begin{array}{l}\mathrm{H} \text {, doble línea, estr. } \\
\text { laterales }\end{array}$ & oscuridad, llamas, salida del sol & \\
\hline Vindobonensis 20 (2 ex) & & simbólica & $\mathrm{H}$, doble línea & $\begin{array}{l}\text { decapitación (¿̨maguey?), hule } \\
\text { ardiendo }\end{array}$ & 4 Movimiento, \\
\hline Vindobonensis 22 & & topónimo & $\mathrm{H}$, doble línea & $\begin{array}{l}\text { decapitación, maguey, malacate, } \\
\text { pelota }\end{array}$ & $\begin{array}{l}2 \text { Perro, II Serpiente } \\
\text { Decapitada }\end{array}$ \\
\hline Vindobonensis 29 & & $\begin{array}{l}\text { simbólica, } \\
\text { ¿topónimo? }\end{array}$ & $\begin{array}{l}\mathrm{H} \text {, doble línea, grecas } \\
\text { laterales }\end{array}$ & fecha, individuo, jaguar & Io Lagarto \\
\hline Vindobonensis 43 & & topónimo & $\begin{array}{l}\mathrm{H} \text {, doble línea, estr. } \\
\text { laterales }\end{array}$ & cerro, fecha, estrellas & \\
\hline Vindobonensis 44 (2 ex) & & $\begin{array}{l}\text { topónimo (Juego } \\
\text { de la noche) }\end{array}$ & $\begin{array}{l}\mathrm{H} \text {, doble línea, estr. } \\
\text { laterales }\end{array}$ & cerro, llamas, oscuridad & \\
\hline Vindobonensis & & $\begin{array}{l}\text { topónimo } \\
\text { (Tlachmalacac) }\end{array}$ & $\begin{array}{l}\mathrm{H} \text {, doble línea, estr. } \\
\text { laterales }\end{array}$ & malacate, pelota, camino & \\
\hline Xolotl9 & 2 & histórica, cancha & $\mathrm{H}$, doble línea, anillos & dos individuos & Nezahualcóyotl, Coyohuatzin \\
\hline Xolotl io & & histórica, cancha & $\mathrm{H}$, doble línea, anillos & dos individuos & Nezahualcóyotl, Coyohuatzin \\
\hline
\end{tabular}

